Portland State University

PDXScholar

Summer 9-3-2015

\title{
Supervisor-Specific Outcomes of a Work-Family Intervention: Evidence from the Work, Family, \& Health Study
}

MacKenna Laine Perry

Portland State University

Follow this and additional works at: https://pdxscholar.library.pdx.edu/open_access_etds

Part of the Psychology Commons

Let us know how access to this document benefits you.

\section{Recommended Citation}

Perry, MacKenna Laine, "Supervisor-Specific Outcomes of a Work-Family Intervention: Evidence from the Work, Family, \& Health Study" (2015). Dissertations and Theses. Paper 2509.

https://doi.org/10.15760/etd.2506

This Thesis is brought to you for free and open access. It has been accepted for inclusion in Dissertations and Theses by an authorized administrator of PDXScholar. Please contact us if we can make this document more accessible: pdxscholar@pdx.edu. 
Supervisor-Specific Outcomes of a Work-Family Intervention:

Evidence from the Work, Family, \& Health Study

by

MacKenna Laine Perry

A thesis submitted in partial fulfillment of the requirements for the degree of

\author{
Master of Science \\ in \\ Psychology
}

Thesis Committee:

Leslie B. Hammer, Chair

Todd Bodner

Ryan Olson

Portland State University

2015 
(C) 2015 MacKenna Laine Perry 


\begin{abstract}
Workplace interventions provide a practical and important means of providing support for employees’ work-family needs. However, work-family interventions are rare and are generally not thoroughly evaluated. The current study seeks to better understand the impacts of STAR (“Support. Transform. Achieve. Results.”), the large-scale work-family intervention developed and implemented by the Work, Family, \& Health Network (see Bray et al., 2013). Drawing on Conservation of Resources theory (Hobfoll, 1989), this study examines supervisors' participation in STAR through assessment of three primary supervisor-specific outcomes: training-related views and behaviors, well-being, and the work-family interface. The sample, consisting of 184 supervisors from 30 extended-care facilities throughout the northeastern United States, comes from archival data that were collected by the Work, Family, \& Health Network. Results show a lack of support for STAR intervention effects on supervisor-level outcomes. Despite the lack of statistically significant effects on supervisors, it is important to note the lack of iatrogenic effects, indicating that participation in the STAR intervention did not harm supervisor outcomes. Implications, future directions, and limitations of the study are discussed.
\end{abstract}




\section{Acknowledgements}

I would like to express my deepest gratitude to my thesis committee for their expertise, feedback, and support. I am especially grateful to my advisor, Dr. Leslie Hammer, for sharing her immense knowledge, sincere encouragement, and generous guidance throughout this project. I would also like to thank Tori Crain for her endless support and caring, thoughtful advice. I am filled with gratitude for my family members-particularly my parents, my sister, and my partner — and owe so much to their infinite love and support. Finally, I would like to express my deep appreciation for my cohort, colleagues, and friends for their help, time, and encouragement. Thank you all so much! 


\section{Table of Contents}

Abstract.................................................................... i

Acknowledgements........................................................ ii

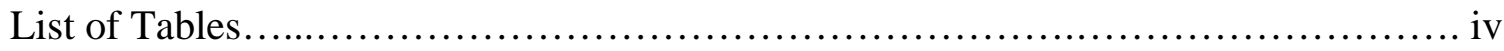

List of Figures.................................................................

Chapter 1

Introduction...................................................................... 1

Chapter 2

Methods....................................................................... 25

Chapter 3

Results......................................................................... 30

Chapter 4

Discussion................................................................... 35

Figures..................................................................... 43

Tables...................................................................... 44

References..................................................................... 48

Appendix

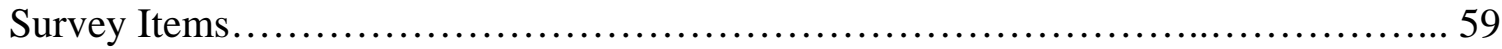


List of Tables

Table 1: Means by Condition Over Time........................................ 44

Table 2: Descriptive Statistics for and Correlations Among Key Study Variables.......... 45

Table 3: General Linear Mixed Model Results for Intervention Effects on Supervisor

Outcomes..................................................................... 47 
WORK-FAMILY INTERVENTION

List of Figures

Figure 1: Hypothesized Model................................................... 40 


\section{Chapter 1: Introduction}

Workplace, societal, and economic conditions over the past several decades have led to changes in the demands placed on workers to fulfill the responsibilities of their work and family roles (Kossek \& Lambert, 2005; Neal \& Hammer, 2007). For instance, there have been increases in the number of dual-earner couples, working single parents, and “sandwich generation” employees, or those workers responsible for caring for both their children and their aging parents. Gender integration in the workforce and volatile economic conditions place additional stress on working families. However, despite growing demands on workers, rising concern for employees’ work-family needs, and mounting evidence that work-family policies benefit both employees and organizations, widespread changes in business practices have not occurred (Kossek, Hammer, Kelly, \& Moen, 2014).

The lack of large-scale changes in work-family policies may be largely due to a scarcity of evidence-based work-family policy options. Formal, rigorous evaluation of implementation and effectiveness of work-family policies is important to provide empirically-validated recommendations that organizations can confidently use to help reduce work-family conflict and improve organizational outcomes. However, most existing research is cross-sectional and correlational, providing little basis for causal inferences (Hammer, Demsky, Kossek, \& Bray, 2015). A small number of workplace interventions have been designed to provide family-friendly policies that improve wellbeing, but experts regard those interventions targeting job stress and work-family conflict 
as generally poorly designed and implemented (LaMontagne, Keegel, Louie, Ostry, \& Landisberg, 2007; Kossek et al., 2014).

Though few work-family interventions are formally evaluated, researchers see a lack of attention paid to work-family and well-being outcomes in those evaluations that do occur (Brough \& O’Driscoll, 2010; Kelly et al., 2008). Furthermore, these workfamily interventions have been assessed almost exclusively from the perspective of employee outcomes, with little to no attention to supervisors’ needs, experiences, and outcomes. Because supervisors hold a unique and important role in organizations, consideration of ways to improve supervisor-specific outcomes and supervisors’ experience of training programs is vital to the creation of effective training programs and interventions that improve each organization as a whole. Furthermore, researchers report that actual work-family practices are often based on supervisor discretion, rather than formal workplace policy (Beehr, Farmer, Glazer, Gudanowski, \& Nair, 2003). Thus, study of ways to improve supervisors' attitudes and behaviors surrounding work-family policies may impact not only supervisors, but organization- and employee-level outcomes, as well. By exploring these issues explicitly through rigorous empirical research, future work-family intervention processes can be tailored to suit organizational and personal needs.

\section{Primary Contributions}

The current study presents three primary contributions to current work-family and intervention literature. First, the current study helps address the need for thorough 
empirical assessment of work-family interventions (Hammer et al., 2015; Kossek et al., 2014). Workplace intervention research has been quite rare in general (Scharf et al., 2008), but work-family interventions are especially so, with very few work-family intervention studies published at all (Casper, Eby, Bordeaux, Lockwood, \& Lambert, 2007). Furthermore, whereas the vast majority of past research on work-family policies and interventions has been cross-sectional and correlational (Hammer et al., 2015), the current study assesses intervention effects on supervisor outcomes from a longitudinal perspective, over a 12-month time period in a group-randomized control trial design.

Second, the current study is the first, to my knowledge, to examine supervisorspecific outcomes of a work-family intervention that is largely targeted at supervisors. In general, leadership and supervision studies often fail to focus on the supervisors' perspective. Barling, Christie and Hoption (2010) state that studies have generally “considered leadership effectiveness at the level of the follower, the group, and the organization” (p. 205). Even those interventions specifically targeted at supervisors are not typically assessed from the supervisor's own perspective, beyond simple learning outcomes (i.e., whether the supervisor learned the training material). By failing to consider the effects leadership and supervisory training can have on leaders and supervisors themselves, especially in the well-being and work-family domains, researchers are missing an important level of analysis related to workplace interventions. Moreover, the current study considers both positive and negative effects interventions may have on supervisors. For example, supervisor-targeted interventions may increase 
demands on supervisors by changing job responsibilities or increasing workload, even while benefitting supervisors by increasing the resources available to them.

Understanding both benefits and potential drawbacks of work-family interventions allows researchers and practitioners to design interventions that maximize positive effects on workers across levels of organizations.

Finally, the current study contributes to the work-family literature by assessing supervisors of a low-wage, hourly workforce in the healthcare industry. Little work has been conducted to evaluate the ways in which shift workers are most effectively managed and supported, particularly in regard to work-family needs, but even less research has examined supervisors of these hourly employees. Interventions may impact supervisors differently, depending on the context in which they work. Furthermore, because supervisors of low-wage workers hold positions allowing direct improvement of the lives of disadvantaged employees and their families, supervisors provide an important lever for change in the workplace. By studying the effects of work-family workplace interventions on supervisors directly, researchers can use empirical findings to demonstrate to organizations and management of all levels how interventions may impact all individuals_-including supervisors_ — and the workplace as a whole, furthering the effective use of interventions as a strategy for change that benefits employees and organizations.

\section{Current Study}

The current study examines supervisors’ participation in a large-scale work- 
family intervention called STAR (“Support. Transform. Achieve. Results.”) through assessment of three primary outcomes: well-being, training-related views and resources, and the work-family interface. I will first introduce Conservation of Resources theory as a framework for exploring the effects of the STAR intervention on supervisors. Then, I will provide an overview of past interventions and describe the STAR intervention. Drawing primarily upon Conservation of Resources theory, I will then propose several research questions and hypotheses targeting supervisor outcomes of the intervention and review relevant literature. I will next describe the methods used to conduct this study. Finally, I will present the results and discuss limitations, future directions, and implications of the study.

\section{Conservation of Resources Theory}

Conservation of Resources (COR) theory states that individuals are motivated to obtain, maintain, and protect resources (Hobfoll, 1989). These resources can be conditions, objects, personal characteristics, or energies. Conditions are considered resources when they are valued and sought after. Conditions could include supervisor status or marital status. Objects can be resources based on their physical features or because of an additional status value, such as may be provided by a vehicle or a house. Personal characteristics, such as self-esteem and optimism, are considered resources primarily when they buffer stress processes. Finally, energies are those resources that help individuals to acquire new resources. Energies may include time, money, or knowledge, which can all be invested toward gain of other resources. According to COR 
theory, strain can result from actual resource loss, threat of resource loss, or lack of resource gain when another resource has been invested (Hobfoll, 1989).

The current study is designed to assess the STAR intervention, using COR theory as a framework to understand supervisor outcomes. Based on this framework, the STAR intervention may both positively and negatively affect participating supervisors. On one hand, STAR may benefit supervisors through several types of resource gains. One potential resource gain could occur through new knowledge, skills, and abilities supervisors received as they learn about and implement control over work and supportive behaviors. A second source of resource gain may come from supervisors’ own supervisors (e.g., top-level management). STAR is designed to be presented across organizational levels, so higher-level supervisors also receive the intervention. Therefore, supervisors are likely provided with resources (e.g., control over work, support for workfamily needs) through the intervention, just as employees are.

On the other hand, STAR may also have negative impacts on supervisors through resources lost or perceived to be threatened. Because STAR involves several supervisorspecific tasks and training sessions, in addition to those sessions that all employees participated in, STAR likely increases work-related demands on supervisors. These demands could be perceived as threats of resource loss or as actual resource loss. For example, this study focuses on implementation of STAR in the extended care industryan industry where job tasks often depend on patient needs. If supervisors are unable to adjust other work demands to accommodate the demands of participation in STAR due to 
the nature of their jobs, supervisors could lose valued time spent on other tasks, whether in the work or non-work domain.

\section{The STAR Intervention}

\section{Past Work-Family Interventions}

Past work-family research has shown mixed results of the direct effects of workfamily initiatives and interventions on work-family conflict and enrichment (Kelly et al., 2014). Work-family interventions are still quite rare, and measurement issues, such as differences between policy use and policy availability, make strong conclusions difficult to reach (Kelly et al., 2014). Furthermore, those few initiatives and interventions that organizations do undertake are typically evaluated in cross-sectional, correlational designs, if they are evaluated at all.

Work-family interventions have rarely been evaluated for impact on well-being and work-family outcomes (Brough \& O’Driscoll, 2010; Kelly et al., 2008). Several recent studies have provided notable exceptions. First, Kelly and colleagues (2011) examined the Results Only Work Environment (ROWE) initiative at Best Buy Co., Inc. corporate headquarters, finding that the ROWE intervention led to increased control over work and improved work-family outcomes, compared to employees in control departments. Second, Hammer and colleagues (2011) evaluated effects of a familysupportive supervisor support intervention in 12 grocery stores, finding that the intervention improved well-being, job satisfaction, and turnover intentions for those employees experiencing high baseline work-to-family conflict, while the intervention 
worsened the same outcomes for employees experiencing low baseline work-to-family conflict. To explain these mixed results, Hammer and colleagues suggest that workfamily interventions “may be most effective for those most in need” (p. 147).

Within the published studies on the STAR intervention, three studies focus on well-being and work-family outcomes in particular, helping to fill this gap in the literature. Kelly and colleagues (2014) evaluated STAR in a group of information technology employees, finding modest effects of the intervention on work-family conflict, family time adequacy, control over work, and family-supportive supervisor behaviors. Olson and colleagues (2015) found that STAR intervention group employees experienced greater actigraphy-measured sleep duration and reduced sleep insufficiency at 12-month follow-up, when compared with control group employees. Finally, Davis and colleagues (2015) found that intervention group parents showed a significant increase in parent-child shared time at 12-month follow-up, while control group parents showed a decrease in parent-child shared time at 12-month follow-up. Despite these important contributions to understanding of work-family intervention outcomes at the employee level, the authors did not assess supervisor-level outcomes in any of these studies.

\section{Supervisors in Interventions}

Though researchers have begun to meet the call for evaluation of well-being and work-family outcomes, the current study seeks to further address this gap in the literature by assessing the effects of the intervention on supervisors. STAR is specifically designed to include supervisor-specific intervention strategies, with additional training elements 
designed for supervisors above and beyond those training components provided to employee participants. Klein and Kozlowski (2000) emphasized the importance of expanding training evaluations across multiple levels. By examining the effects of the intervention on supervisors directly, instead of focusing on employee outcomes alone, we can better understand how STAR and other workplace interventions may impact both individuals and the workplace as a whole. By assessing effects of the intervention on well-being, training-related views and resources, and the work-family interface, the current study provides a detailed look at the ways in which STAR impacts supervisors.

\section{Support. Transform. Achieve. Results.}

The STAR intervention is based on a conceptual model developed by members of the Work, Family, \& Health Network (WFHN). The overall model proposes, based on theoretical and empirical support, that the STAR intervention will lead to reductions in work-family conflict through improved employee workplace perceptions and, additionally, that reductions in work-family conflict will lead to workplace, employee, and family outcomes (King et al., 2012). Furthermore, the model suggests several moderators of these relations, such as demographic factors, job or family characteristics, and social support. Using the WFHN conceptual model as a framework, the STAR intervention merges Phase 1 research together, tying the ROWE intervention at Best Buy Co., Inc. headquarters (Kelly et al., 2011; Moen, Kelly, Tranby, \& Huang, 2011) to FSSB initiatives in Spartan grocery stores (Hammer et al., 2011) to create a single intervention that targets work practices regarding work time, work location, and support for 
employees’ work-family needs (see King et al., 2012; Kossek et al., 2014).

Because the Work, Family, and Health Study seeks to create an intervention that would improve control over work hours and support for employees’ work-family needs, supervisor education to increase supportive behaviors is an important aspect of the intervention design and implementation. STAR therefore involves several unique components for supervisors, above and beyond the training components in which employees participate. For all employees and supervisors alike, the intervention contains a series of participatory sessions and outside activities, designed to present various aspects of the training content to participants and to allow participants to ask questions and discuss intervention-related topics in a group setting. Supervisors are given additional supplementary training, including added participatory sessions designed for supervisors only, computer-based supervisor training, and behavior tracking. All participatory sessions are presented by facilitators hired by an organizational development company that also worked on Phase I of the WFHN.

The supervisor computer-based training and behavior tracking components are known collectively as weSupport. The computer-based training is designed to consist of an hour-long training that supervisors could complete online through the program cTRAIN. This computer-based training specifically targets family and personal support, as well as performance support. Supervisors are trained in concepts and behaviors that could be used to support to their employees, based on Phase I work by Hammer and colleagues (see Hammer et al., 2011). Supervisors take both pretest and posttest quizzes 
throughout the computer-based training.

Following the computer-based training, supervisors participate in the first of two behavior-tracking exercises, each of which lasted two weeks. Supervisors are asked to set goals and track their own behaviors using an iPod application. This tracking exercise is based on the behavioral self-monitoring training method, which has successfully been applied in both psychological and physiological contexts (Barton, Blanchard, \& Veazey, 1999; Korotitsch \& Nelson-Gray, 1999).

The design of the STAR intervention is different from that of other work-family interventions in several significant ways. First, STAR targets entire groups of employees in a collective manner, using an organizational, multi-level approach to workplace change. Kossek and colleagues (2014) refer to STAR as a work "redesign” intervention. Rather than targeting individuals alone, STAR uses the workplace as a whole to engage administrators, supervisors, and employees in new practices, including shifting control over schedules from supervisors to employees and changing interactions between supervisors and employees toward improving support for work-family needs. Second, STAR combines participatory changes with organized training and behavioral selfmonitoring, using multiple training delivery methods to maximize learning and transfer. These "blended” training methods, combining forms of traditional face-to-face delivery and computer-based instruction, are associated with higher motivation to learn, among other outcomes (Klein, Noe, \& Wang, 2006). The use of behavioral self-monitoring provides a unique opportunity for supervisors to initiate and reinforce family-supportive 
behaviors learned throughout training. In their review of occupational health, productivity, and safety interventions, Olson and Winchester (2008) recommend the use of behavioral self-monitoring methods in multi-component interventions like STAR, based on the strong impacts on outcomes in previous occupational interventions they reviewed. STAR uses these effective methods in an effort to improve workplace outcomes by "adapting the environment rather than the individuals” (p. 334, King et al., 2012). By attempting to reduce exposure to stressors, instead of treating stressors after their occurrence, STAR presents a primary, preventative approach to workplace training. The STAR materials are available for free download from the Work, Family, \& Health Network website (http://projects.iq.harvard.edu/wfhn/toolkits-achieve-workplacechange).

\section{Outcomes}

The current study examines three primary outcomes for supervisors, assessing differential change across treatment groups in a 12-month time period. I will next turn to discussion of these three primary outcomes: supervisor training-related views and resources, supervisor well-being, and the supervisor work-family interface. In the following discussion, I hypothesize STAR will positively impact the first outcome category (i.e., supervisor training-related views and resources). However, because of the complex role that supervisors play in the STAR intervention, both receiving resources for their own use and providing resources for others' use, the latter two outcome categories (i.e., well-being, work-family interface) will be presented as research questions. Please 
see figure 1 for the hypothesized model.

\section{Supervisor Training-Related Views and Resources}

Views of flexible work arrangements and productivity. Over recent years, the

need for work-family policies has been increasingly acknowledged at both the organizational and national levels. The 1993 Family and Medical Leave Act, which requires all companies of over 50 employees to offer unpaid leave, brought work-family policies to the national stage. Since then, workplaces have begun to offer a wider selection of formal work-family policies, including flexible work arrangements, such as paid leave, parental leave, sick leave, part-time work, and flextime (i.e., varying beginning and end time of work days). Results of research on the impact of leave policies on work-family conflict are mixed, with only some paid leave policies significantly benefitting employees’ work-family conflict (Allen et al., 2014). However, Allen and colleagues (2014) found some evidence that leave policies are most beneficial for employees when employees perceive support from the organization and supervisors. This and other research suggests that formal policies begin the process of addressing employees’ work-family needs, but they are far from sufficient.

Research has shown that it is the supervisors' informal support of policies that determine whether formal policies are actually utilized (Kelly \& Kalev, 2006; Lambert \& Waxman, 2005). One barrier to supervisor support of work-family policies is supervisors' attitudes about how use of policies impacts organizational outcomes, such as productivity. Kossek, Barber, and Winters (1999) found that, in a sample of about 1,000 
managers, past/current use of flextime and future use of flextime were significantly lower when associated with productivity concerns. Furthermore, Kossek and colleagues found that peer use was a consistent predictor of past/current use and of future use, across three different flexible work arrangements. These results indicate that reducing or eliminating any negative views of flexible work arrangements and increasing supervisory peers’ usage of flexible work arrangements will benefit supervisors and employees alike. STAR is designed to impact both, providing resources in the form of training for supervisors that specifically targets their views of flexible work arrangements and helps employees to use flexible work arrangements much more widely. The knowledge, skills, and abilities acquired through participation in STAR, along with experience of more individuals using flexible work arrangements in the organization, are expected to act as resources that improve supervisors’ attitudes.

Hypothesis 1: Participation in the intervention will be associated with decreased negative views of flexible work arrangements for supervisors participating in STAR, when compared with control supervisors.

Family-supportive supervisor behaviors. Three factors are thought to contribute to employees' perceptions of family-related support received from supervisors, including formal policies (e.g., organizational; national), culture and climate (e.g., work-family climate), and family-supportive supervisor behaviors (Hammer, Kossek, Anger, Bodner, \& Zimmerman, 2007). Family-supportive supervisors exhibit empathy toward an employee’s desire to seek balance between work and family responsibilities (Thomas \& 
Ganster, 1995). Hammer and colleagues (2009) identify four components of FSSB, representing ways supervisors can exhibit their support for employees' family roles: emotional support, instrumental support, role-modeling behavior, and creative workfamily management. FSSB has been tied to reductions in work-family conflict, indicating its important influence on work-family outcomes (Kossek, Pichler, Hammer, \& Bodner, 2011). Additionally, FSSB is significantly related to improved job satisfaction, reduced turnover intentions, increased control over work hours, and reduced perceived stress (Hammer, Kossek, Bodner, \& Crain, 2013).

The current study examines supervisors’ perceptions of FSSB performed by their own higher-level supervisors (i.e., top-level managers). To the best of my knowledge, no research has yet examined supervisors' experiences of received FSSB. Because STAR is implemented across all levels of the organization, supervisors' own supervisors are also able to participate in STAR. One major component of STAR is a computer-based training and behavior-tracking exercise for supervisors to increase FSSB. Thus, increases in perceived FSSB that would be expected for employees as a result of STAR should extend to supervisors' experiences as well, such that supervisors should perceive increased support for their own family needs following the intervention. Hobfoll and colleagues’ (1990) extension of COR theory proposes that social support is a primary way in which an individual's pool of available resources can be widened. Perceived FSSB are expected to be increased through participation in STAR, as supervisors' own supervisors also received training to increase FSSBs. 
Hypothesis 2: Membership in the intervention condition work sites will be positively related to supervisors’ perceptions of their own supervisors’ FSSBs.

Control over work. Generally speaking, there are two forms flexible work arrangements can take: temporal flexibility, also known as flextime, and spatial flexibility, also known as flexplace. Availability of flexible work arrangements is shown to reduce health symptoms of stress, improve job commitment, and reduce costs for employers through such means as decreased absenteeism (Halpern, 2005). However, empirical relations between flexible work arrangements and work-family conflict have been mixed (Shockley \& Allen, 2007). Finer-grained analyses have shown that availability of flexible work arrangements is more strongly related to work-to-family conflict than family-to-work conflict (Shockley \& Allen, 2007). However, other avenues for disentangling the effects of flexible work arrangements on workers should be examined.

One such avenue for exploration is control over work, or the ability to decide when and where one works (Kelly \& Moen, 2007). Perception of control over work has been identified as an important mediator between workplace policies/practices and outcomes such as work-family conflict (Thomas \& Ganster, 1995; Kelly \& Moen, 2007). Flexible work arrangements by themselves don’t often lead to changes in assumptions that it is supervisors who control when and where employees work (Kelly \& Kalev, 2006), but research shows that specifically targeting control over work benefits workers by reducing work-family conflict and improving work-family fit (Kelly, Moen, \& 
Tranby, 2011). The STAR intervention is designed to target experiences of control over work in addition to organizational policies of flexible work arrangements, rather than focusing on only availability of policies, as is often the case in organizations.

Control-either more general job control or the schedule-specific control discussed here- — can act as a resource on its own or serve as a link with other important resources (Westman, Hobfoll, Chen, Davidson, \& Laski, 2004; Hobfoll, 1998). One major corollary of COR theory proposes that those who lack resources are more vulnerable to resource loss, while another corollary posits that those who possess resources are more capable of resource gain (Hobfoll \& Shirom, 2001). Westman and colleagues (2004) discuss sense of control as part of a resource caravan, or aggregated set of resources, that can benefit outcomes directly or through combination with each other. Because supervisors' own supervisors are able to participate in STAR, which is targeted across levels of the organization, supervisors should generally receive the same benefits of STAR as employees. The STAR intervention focuses heavily on increasing control over work, using team-level redesign principles (Kossek et al., 2014). The systematic effort to change workplace practices around job design during STAR is ideally not limited to employees only, but rather extends throughout the entire work group and throughout the organization as a whole. As such, supervisors should receive increases in control over work in the same manner as employees. In line with COR theory, I propose that control over work will act as a resource for supervisors and will be increased through membership in the intervention condition work sites. 
Hypothesis 3: Membership in the intervention condition work sites will be positively related to supervisors' perceptions of their own control over work.

\section{Well-being}

Burnout. Burnout is the strain response that stems from stressful work experiences (Halbesleben, 2006; Maslach, 1982). Maslach (1982; 1998) established a widely used, multidimensional theory of burnout that consists of three components: emotional exhaustion, depersonalization, and personal accomplishment. Emotional exhaustion is the central dimension of burnout, as well as the most widely reported and assessed (Maslach, Schaufeli, \& Leiter, 2001). Additionally, emotional exhaustion represents the "stress" component of burnout, often causing individuals to withdraw from work to cope with overload (Maslach et al., 2001). Based on the COR framework, the current study focuses on the emotional exhaustion dimension of burnout. Burnout as a whole has been associated with a wide variety of outcomes, including increased turnover intentions and actual turnover, decreased job satisfaction, and decreased organizational commitment (Maslach et al., 2001). It is the emotional exhaustion component, however, that is most strongly associated with health and well-being. Because emotional exhaustion is in itself a measure of well-being and is theoretically the most relevant to health and well-being concerns (Shirom, 2009), it has been the focus of empirical attention. For example, Ahola and colleagues (2009) report that emotional exhaustion predicted hospitalization for cardiovascular disease, as well as work disability from mental disorders in a longitudinal study of almost 8,000 Finnish employees. 
Scholars have begun to address burnout related to the work-family interface, as well. In a study of 686 hospital nurses, work-to-family conflict, family-to-work conflict, and stress from organizational changes were associated with significantly higher levels of burnout (Burke \& Greenglass, 2001). Innstrand and colleauges (2008) later found evidence of a reciprocal relationship between the work-family interface and burnout, including both conflict and facilitation variables in both directions (i.e., work-to-family and family-to-work). This indicates the importance of improving burnout and workfamily outcomes to prevent loss spirals, when loss of resources results in further depletion of resources (Hobfoll \& Shirom, 2001), and promote gain spirals, when initial resource gains results in additional gains (Hobfoll \& Shirom, 2001).

Past research has strongly tied burnout to the COR framework. Halbesleben’s (2006) meta-analysis of burnout and social support builds upon this basic framework. Scholars theorize that stress leads employees to burn out over time because the rate of resource usage due to work demands outweighs the rate with which resources are provided to replenish those used to meet demands (Freedy \& Hobfoll, 1994). Halbesleben (2006) found that social support within the work domain (e.g., support from supervisors or coworkers) is most strongly related to the emotional exhaustion component of burnout, while non-work social support (e.g., support from spouses, family, or friends) is most strongly related to the other components of burnout. Other research shows that empowered work environments are linked to lower burnout and improved health and well-being in a sample of nurse managers (Laschinger, Almost, Purdy, \& Kim, 2004). 
STAR likely both provides resources and causes resource loss or threat of resource loss for supervisors. Resources are likely gained through increased workplace social support that supervisors receive from their own higher-level supervisors who also participate in the intervention. Additionally, STAR is designed to increase control over work for participants, so supervisors should also gain resources through an increase in their own control over work. However, supervisors also likely experience resource loss or threat to resources because of increased demands associated with participating in STAR. Supervisors are responsible for allowing lower-level employees to improve their own control over work and for providing increased support to their own employees, both of which may add demands that cause loss of or threat to valued resources, in addition to the impacts of added demands from participating in training sessions. Furthermore, supervisors may already possess a higher level of control over work than their employees, due to the nature of their positions. Overall, COR theory suggests that the resources gained by participation in the intervention may reduce strain experienced in the form of burnout while resources lost or threatened by participation in STAR may increase strain in the form of burnout.

Research question 1a: Is participation in the intervention associated with increased or decreased burnout for supervisors participating in STAR, when compared with control group supervisors?

Job satisfaction. Job satisfaction is defined as an affective appraisal or orientation an individual has of or toward their work (Grandey, Cordeiro, \& Crouter, 
2005; Price, 2001). Two different approaches to job satisfaction are commonly held in the literature: the global approach, which is an overall affective response to a job, and the composite approach, which considers separate attitudes about different parts of the job (Bruck, Allen, \& Spector, 2002). In the composite approach, attitudes about components of a job may vary wildly within one individual. Spector (1997) summarized these various components into a list including the following: appreciation, communication, co-workers, fringe benefits, job conditions, nature of the work itself, nature of the organization itself, organizational policies and procedures, pay, personal growth, promotion opportunities, recognition, security, and supervision

Both forms of job satisfaction have been tied with work-family variables. Bruck and colleagues (2002) found significant relations between work-family conflict and both global and composite job satisfaction. Similar relations were shown using both family-towork conflict and work-to-family conflict as components of work-family conflict more generally.

Research by Grandey and colleagues (2005) shows that work-to-family conflict has a significant effect on job satisfaction, above and beyond the effects of other established predictors. Based on this evidence, Grandey and colleagues suggest that organizations should attempt to reduce work-to-family conflict. STAR is designed to aid in this effort to reduce the interference of work with family demands by providing more support for work-family needs (e.g., FSSBs) and more ability to shape work demands around family demands (e.g., control over work). Because supervisors receive additional 
resources through the STAR intervention, including increased support from their own supervisors (e.g., top-level management) who also participate in STAR and increased control over their own schedules, supervisors may be better able to prevent resource loss and achieve resource gain. Within the work domain, the addition of resources may improve job satisfaction by helping supervisors to experience less strain. On the other hand, because STAR places additional work-related demands on supervisors through added job-related responsibilities of providing new support to employees, above and beyond support supervisors already gave, resources may be lost or threatened by participation in the intervention. Thus, the STAR intervention may alternatively decrease job satisfaction.

Research Question 1b: Is participation in the intervention associated with increased or decreased job satisfaction for supervisors participating in STAR, when compared with control group supervisors?

\section{Work-Family Interface}

Work-family conflict. Greenhaus and Beutell (1985) defined work-family conflict (WFC) as "a form of interrole conflict in which the role pressures from the work and family domains are mutually incompatible in some respect” (p. 77). This conflict is known to exist in two directions: work-to-family conflict (WTFC), in which the work role interferes with the family role, and family-to-work conflict (FTWC), in which the family role interferes with the work role (Frone, 2003). WTFC and FTWC are often differentiated in research because of their unique variance, despite some overlap 
(Mesmer-Magnus \& Viswesvaran, 2005). Using meta-analytic methods, Amstad and colleagues (2011) found that both directions of conflict are consistently related to workdomain outcomes (e.g., job satisfaction, turnover intentions, work-related performance), family-domain outcomes (e.g., marital satisfaction, family-related stress), and domainunspecific outcomes (e.g., psychological strain, somatic/physical symptoms, depression), though outcomes in the same domain as the source of conflict held the strongest relations. Antecedents of WTFC and FTWC have also been widely studied, with meta-analytic results revealing significant influences of a broad variety of work-specific and familyspecific variables (Byron, 2005). Though Byron showed that some of the strongest predictors influence both WTFC and FTWC, such as job stress, family stress, and family conflict, she argues that there is evidence for differentiation of directionality based on differences in strength of predictors, as well as evidence of some unique predictors.

Because of the known relations between WFC and important outcomes at both the individual and organizational levels, reduction of WFC has great value for employees, supervisors, and organizations alike. Grandey and Cropanzano (1999) tested a CORbased model of WFC, finding that resource loss from work and family stressors led to decreased job and family satisfaction, increased life distress, and decreased physical health. Resources provided by the STAR intervention may reduce both WTFC and FTWC, such that the additional support supervisors receive from their own higher-level supervisors who participate in STAR, as well as increased ability to control their own schedules because of organizational changes implemented in STAR, may increase ability 
of supervisors to meet the demands of work and family. However, because STAR trains supervisors to engage in family-supportive behaviors with their employees and to help employees increase control over work, supervisors may lose resources or feel threat of loss, due to added job-related responsibilities. This reduction in resources may cause supervisors to be less able to meet demands of work and family, thus increasing WTFC or FTWC.

Research question 2a: Is participation in the intervention associated with increased or decreased WTFC for supervisors participating in STAR, when compared with control group supervisors?

Research question $2 b$ : Is participation in the intervention associated with increased or decreased FTWC for supervisors participating in STAR, when compared with control group supervisors?

Work-family positive spillover. Though researchers have paid much attention to work-family conflict over the past several decades, significantly less research has focused on the beneficial impact work and family roles can have on each other. Introduction of such constructs as work-family positive spillover (Edwards \& Rothbard, 2000), in addition to other closely related constructs such as work-family enrichment (Greenhaus \& Powell, 2006), opened new doors for exploration of the work-family interface. Workfamily positive spillover (WFPS) has been defined as "transfer of positively valenced affect, skills, behavior, and values from the originating domain to the receiving domain, thus having beneficial effects on the receiving domain” (Hanson, Hammer, \& Colton, 
2006, p. 251). Researchers have generally considered WFPS and WFC to be separate constructs, such that individuals can have high levels of both WFPS and WFC simultaneously (Greenhaus \& Powell, 2006; Hanson et al., 2006).

Work-family research has begun to explore theoretical background for WFPS and other facilitation-type work-family variables. Wayne and colleagues (2007) constructed a theory known as Resource-Gain-Development (RGD) to help fill this gap. Drawing on several theories, including COR theory, the RGD perspective suggests that individuals tend toward higher levels of functioning in roles, such as work and family roles, by gathering resources (Wayne et al., 2007). Facilitation processes, according to one main proposition of RGD, are enabled by resource gain. Greenhaus and Powell (2006) also offered a theoretical model focusing on work-family enrichment processes, which suggests that resources from one role lead to high performance and positive affect in that role's domain, and that these increases in performance and positive affect are associated with high performance in another domain. This model also proposes that resources from one role can directly influence performance in another role. Based on both Wayne and colleagues' (2007) model and Greenhaus and Powell’s (2006) model, providing workrelated resources to supervisors through participation in STAR may benefit supervisors in the family domain through work-to-family positive spillover. However, due to demands STAR places on supervisors to learn new behaviors and support employees, resources may be lost or threatened, leading to decreases in work-to-family positive spillover. Because STAR resources are specifically targeted at changing the work role to improve 
management of both work and family demands, the current study considers work-tofamily positive spillover only, though family-to-work positive spillover also exists as a construct/process.

Research question 3: Is participation in the intervention associated with increased or decreased WFPS for supervisors participating in STAR, when compared with control group supervisors? 


\section{Chapter 2: Methods}

\section{Participants}

The Work, Family, \& Health Study (WFHS) is a large-scale, transdisciplinary study implementing STAR as a multi-site randomized control trial work redesign intervention in two industries (see Bray et al., 2013). As a part of the larger WFHS, the current study assesses intervention effects on supervisors in the long-term healthcare industry. Using archival data collected by the WFHN, the current study examines 184 supervisors from 30 extended-care facilities throughout the northeastern United States. The supervisor sample includes upper level management (e.g., administrators, directors of nursing) and middle management (e.g., unit managers, charge nurses). The average age of supervisors is $45.79(S D=10.48)$. Approximately 88.6 percent of the supervisor sample is female. The average number of hours worked at baseline data collection is 47.6 hours per week $(S D=9.0)$. The mean number of employees supervised by each supervisor is $35(S D=38)$. Sixty-one percent of supervisors hold a regular daytime schedule, 23 percent have a variable schedule, and 7 percent have a regular evening schedule; night shift workers are excluded from the study.

\section{Procedures}

The industry’s Vice President of Development helped to identify extended-care facilities for inclusion, leading to a total of 30 work sites. Work sites were paired into 15 groups of two, and then one work site of each pair was randomly assigned to the control condition and one work site to treatment condition. Recruitment involved site-level 
efforts to gain support from management and produce interest in employees, as well as individual-level efforts to recruit participants through informational sessions within the facilities.

Data were collected from supervisors at baseline, prior to the treatment condition group’s participation in any intervention sessions. Trained interviewers conducted inperson computer-assisted personal interviews (CAPI) using scripts. Each participant was administered an informed consent or assent form and asked to keep a signed copy. CAPI data collection took an average of just less than one hour across supervisors.

Following completion of baseline data collection, the intervention was administered to the treatment condition group. STAR for supervisors consisted of participatory sessions, including multiple supervisor-only sessions and multiple sessions including all employees, outside activities, computer-based training, and supportive behavior tracking. Follow-up surveys administered to all supervisors at 6 months and 12 months after the intervention are used to assess longitudinal change.

\section{Measures}

Supervisor training-related views and resources. Supervisor views of the effect

of flexible work arrangements on productivity were assessed with a six-item measure (Kossek, Barber, \& Winters, 1999), using a five-point Likert-type scale from strongly disagree to strongly agree. Responses were coded such that a higher score indicates stronger views that flexibility would negatively impact productivity. A sample item is: "You worry that allowing more flexibility around hours of work would create problems 
among your subordinates.” Past research indicates a Cronbach’s alpha of .71 (Kossek et al., 1999). The Cronbach’s alpha for the current study is .88 at baseline, .87 at 6 months, and .89 at 12 months.

Family-supportive supervisor behaviors (FSSBs) were assessed with a four-item short form measure (Hammer, Kossek, Bodner, \& Crain, 2013), using a five-point Likerttype scale from strongly disagree to strongly agree. Responses were coded such that a higher score indicates higher reports of family-supportive supervisor behaviors. A sample item is: "Your supervisor works effectively with employees to creatively solve conflicts between work and non-work.” Previous research shows a Cronbach’s alpha of .82 for this measure (Hammer et al., 2013). The Cronbach’s alpha for the current study is .83 at baseline, .89 at 6 months, and .87 at 12 months.

Control over work was assessed with an eight-item measure adapted from the original 14-item instrument (Thomas \& Ganster, 1985), using a five-point Likert-type scale from very little to very much. Responses were coded such that a higher score indicates higher control over work hours. A sample item is: "How much choice do you have over when you begin and end each work day?” The original measurement paper reported a Cronbach’s alpha of .75 (Thomas \& Ganster, 1985). The Cronbach’s alpha for the current study is .76 at baseline, .76 at 6 months, and .81 at 12 months.

Well-being. Two aspects of supervisor well-being were assessed in the current study: job satisfaction and burnout. Job satisfaction was assessed with a three-item measure (Cammann, Fichman, Jenkins, \& Klesh, 1983), using a five-point Likert-type 
scale ranging from strongly disagree to strongly agree. Responses were coded such that a higher score indicates higher job satisfaction. A sample item is: "In general, you like working at your job.” Past research indicates a Cronbach’s alpha of .88 (Cammann et al., 1983). The Cronbach’s alpha for the current study is .85 at baseline, .86 at 6 months, and .93 at 12 months.

Burnout was assessed with the three-item emotional exhaustion component of the Maslach Burnout Inventory (Maslach \& Jackson, 1986), using a seven-point Likert-type scale from never to every day. Responses were coded such that a higher score indicates higher burnout. A sample item is: "You feel emotionally drained from your work. How often do you feel this way?” The emotional exhaustion component shows high Cronbach’s alpha values in past research, with values from .86 to .93 across samples in six countries (Poghosyan, Aiken, \& Sloane, 2009). The Cronbach’s alpha for the current study is .88 at baseline, .88 at 6 months, and .89 at 12 months.

Work-family interface. Three aspects related to the work-family interface were assessed in the current study. First, work-to-family conflict was assessed with a five-item measure (Netemeyer, Boles, \& McMurrian, 1996), using a five-point Likert-type scale from strongly disagree to strongly agree. Responses were coded such that a higher score indicates higher work-to-family conflict. A sample item is: “The amount of time your job takes up makes it difficult to fulfill your family or personal responsibilities.” Family-towork conflict was assessed using the complementary five-item measure (Netemeyer, Boles, \& McMurrian, 1996), using a five-point Likert-type scale from strongly disagree 
to strongly agree. Responses were coded such that a higher score indicates higher familyto-work conflict. A sample item is: "Family-related strain interferes with your ability to perform job-related duties.” Reported alphas for WTFC range from .88 to .89 over three samples, while alphas for FTWC range from .87 to .90 across three samples (Netemeyer et al., 1996). The Cronbach's alpha of WTFC for the current study is .92 at baseline, .93 at 6 months, and .93 at 12 months, whereas for FTWC, alpha is .82 at baseline, .84 at 6 months, and .88 at 12 months

Work-to-family positive spillover was assessed with a four-item measure (Hanson, Hammer, \& Colton, 2006), using a five-point Likert-type scale from strongly disagree to strongly agree. Responses were coded such that a higher score indicates higher work-tofamily positive spillover. A sample item is: "Having a good day at work allows you to feel positive with your family.” The Cronbach’s alpha for this scale is reported as .90 in the original validation paper (Hanson et al., 2006). The Cronbach's alpha for the current study is .85 at baseline, .88 at 6 months, and .88 at 12 months.

\section{Analytical Strategy}

To assess the primary hypothesis that participation in the intervention leads to supervisor outcomes, I utilized SPSS software to conduct intent-to-treat analyses in a generalized linear mixed model (GLMM) framework, in accordance with WFHN analysis agreements. The intent-to-treat model estimates intervention effects from the perspective of assignment of groups to conditions, rather than from the perspective of actual treatment received. These analyses were performed by including both intervention 
and control work sites. In these 3-level GLMM “change-on-change” models, the random effects structures reflect the actual organizational structure at the time of randomization, such that time points are nested within individuals, and individuals are nested within work sites. Additionally, these models account for baseline values of outcome variables. Because multiple waves of data are included in each model, each person controls for themselves and no further control variables need be entered into equations. Assigned condition was used to predict outcomes in a series of models across baseline data, 6month data, and 12-month data. Intervention effects on supervisor outcomes are represented by the condition by wave interactions, which represent differences from baseline to follow-up across conditions.

\section{Chapter 3: Results}

\section{Preliminary Analyses}

Before beginning analyses, predictor and outcome variables were examined for accuracy of data entry, missing values, outliers, and testing of assumptions related to multivariate analyses. Scale scores were computed for all applicable outcomes, including supervisor views of the effect of flexible work arrangements on productivity, familysupportive supervisor behaviors, schedule control, job satisfaction, burnout, work-tofamily conflict, family-to-work conflict, and work-family positive spillover. These scale scores were computed using mean imputation if participants provided $75 \%$ or more of item responses. If less than $75 \%$ of responses were provided, scales and items were subject to listwise deletion. 
All variables were examined for evidence of univariate and multivariate outliers. Univariate outliers were assessed in SPSS using frequency tables, histograms, and zscores, as recommended by Raykov and Marcoulides (2008). Multivariate outliers were assessed using Mahalanobis’ Distance (Tabachnick \& Fidell, 2007). No univariate or multivariate outliers were found.

Next, the data were assessed for assumptions of normality, linearity, and homoscedasticity of residuals. Examination of normal q-q plots of residuals showed relatively substantial deviations from normality in some dependent variables, including job satisfaction, FTWC, and WFPS. However, modeling with and without transformed values for these variables did not reveal results that differed substantively. Thus, the original untransformed values are reported for ease of interpretation. All other variables were found to meet applicable assumptions satisfactorily.

Intraclass correlation coefficients (ICCs) were computed to determine the appropriateness of multilevel modeling. The ICC “measures the proportion of the total variance of a variable that is accounted for by the clustering (group membership) of the cases” (Cohen, Cohen, West, \& Aiken, 2003, p. 537). ICCs range from 0 to 1, with higher values indicating higher dependence. ICCs were computed for all dependent variables, clustered at both the person level (i.e., time points nested within individuals) and the work site level (i.e., individuals nested within groups). Person-level ICCs ranged from .55 to .65 , while group-level ICCs ranged from .05 to .19. The vast majority of ICCs indicated substantial effects of individual and group, supporting the use of multilevel 
models for further analysis.

Table 1 presents model-based means across both the intervention condition and control condition for each time point. Table 2 presents descriptive statistics and intercorrelations among variables from baseline, 6-month, and 12-month data collections. The vast majority of correlations were in the expected direction. None of the correlations that were in the opposite direction of expected were significant. WFPS was the most frequently correlated in the opposite direction of expected (e.g., views of FWAs, burnout), though these correlations were still not significant.

In total, 211 supervisors were eligible to participate in the study. Of these eligible managers, 101 supervisor were assigned to STAR and 110 supervisors were assigned to the control group. Baseline data collection was completed by 184 supervisors, producing a response rate of $87.2 \%$, with 88 supervisors in STAR and 96 in the control group. At the 6-month time point, 161 supervisors were still eligible. Six-month data collection was completed by 154 supervisors, yielding a response rate of $83.7 \%$, with 74 supervisors in STAR and 80 in the control group. Finally, at the 12-month time point, 151 supervisors were still eligible. Twelve-month data collection was completed by 145 supervisors, yielding a response rate of $96.0 \%$, with 69 supervisors in STAR and 76 in the control group.

\section{Hypothesis and Research Question Analyses}

Hypothesis 1 states that STAR will result in decreased negative views of the effects of flexible work arrangements on productivity, relative to the control condition. 
Table 3 provides the results of all general linear mixed model results. The STAR effect on views of flexible work arrangements was not statistically significant at 6 months $(\gamma=$ $0.13, t=-1.05, p=.30)$ or 12 months $(\gamma=-0.10, t=-0.80, p=.43)$, indicating a lack of support for hypothesis 1, though results were in the expected direction. Effect sizes were calculated by estimating differences in mean changes from baseline to each time point across intervention conditions, divided by the square root of the sum of the random effects for each model (see table 3 ). The magnitude of these effects ( $d=.18$ for the 6 month time point; $d=.21$ for 12-month time point) is considered small (Cohen, 1988).

Hypothesis 2 states that STAR will result in increased perceptions of received FSSBs from supervisors’ own supervisors, relative to the control condition. The STAR effect on FSSBs was not statistically significant at 6 months $(\gamma=0.05, t=.39, p=.70)$ or 12 months $(\gamma=-0.03, t=-0.24, p=.81)$, indicating a lack of support for hypothesis 2 . The 6-month effect is in the expected direction, while the 12-month result is opposite of expected. The magnitude of these effects $(d=.14$ for the 6 -month time point; $d=.39$ for 12-month time point) is considered small (Cohen, 1988).

Hypothesis 3 states that STAR will result in increased perceptions of control over work for supervisors, relative to the control condition. The STAR effect on control over work was not statistically significant at 6 months $(\gamma=-0.05, t=-0.49, p=.62)$ or 12 months $(\gamma=-0.07, t=-0.64, p=.53)$, indicating a lack of support for hypothesis 3 . The results for schedule control were not in the expected direction. The magnitude of these effects ( $d=.05$ for the 6 -month time point; $d=.01$ for 12 -month time point) is considered 
small (Cohen, 1988).

Research question 1 explores whether STAR will result in increased or decreased burnout and job satisfaction for supervisors, relative to the control condition. The STAR effect on supervisor burnout was not statistically significant at 6 months $(\gamma=-0.06, t=-$ $0.26, p=.80)$ or 12 months $(\gamma=-0.16, t=-0.73, p=.46)$. Both effects are in the ideal direction, indicating decreased burnout at both 6 and 12 months, despite the lack of statistically significant effect. The magnitude of these effects $(d=.12$ for the 6 -month time point; $d=.32$ for 12-month time point) is considered small (Cohen, 1988). The STAR effect on supervisor job satisfaction was also not statistically significant at 6 months $(\gamma=0.03, t=0.30, p=.77)$ or 12 months $(\gamma=-0.02, t=-0.20, p=.84)$. Only one of these results is in the ideal direction, with the 6-month result indicating higher job satisfaction and the 12-month result indicating lower job satisfaction. The magnitude of these effects ( $d=.24$ for the 6 -month time point; $d=.53$ for 12 -month time point) is considered small for the 6-month time point and medium for the 12-month time point (Cohen, 1988). These results indicate that supervisor burnout and job satisfaction are not significantly impacted, either positively or negatively, by participation in STAR.

Research question 2 explores whether STAR will result in increased or decreased work-to-family and family-to-work conflict for supervisors, relative to the control condition. The STAR effect on supervisor work-to-family conflict was not statistically significant at 6 months $(\gamma=-0.14, t=-1.09, p=.18)$ or 12 months $(\gamma=-0.18, t=-1.36, p$ $=.18$ ). Both of the results for work-to-family conflict are in the ideal direction, despite 
the lack of statistical significance. The magnitude of these effects ( $d=.07$ for the 6 month time point; $d=.05$ for 12-month time point) is considered small (Cohen, 1988). The STAR effect on supervisor family-to-work conflict was also not statistically significant at 6 months $(\gamma=0.04, t=.41, p=.68)$ or 12 months $(\gamma=-0.05, t=-0.52, p=$ .61), with the 6-month result indicating higher family-to-work conflict and the 12-month result indicating lower family-to-work conflict. The magnitude of these effects $(d=.17$ for the 6-month time point; $d=.32$ for 12-month time point) is considered small (Cohen, 1988). These results indicate that supervisor work-to-family and family-to-work conflict are not significantly impacted, either positively or negatively, by participation in STAR.

Finally, research question 3 explores whether STAR will result in increased or decreased work-to-family positive spillover for supervisors, relative to the control condition. The STAR effect on supervisor work-to-family positive spillover was not statistically significant at 6 months $(\gamma=0.03, t=0.31, p=.76)$ or 12 months $(\gamma=0.11, t=$ $1.09, p=.28$ ), indicating that supervisor work-to-family positive spillover is not significantly impacted, either positively or negatively, by participation in STAR. Both of these results are, however, in the ideal direction of increased work-to-family positive spillover. The magnitude of these effects $(d=.07$ for the 6 -month time point; $d=.14$ for 12-month time point) is considered small (Cohen, 1988). 


\section{Chapter 4: Discussion}

Results showed a lack of support for hypotheses 1, 2, and 3, indicating a lack of support for STAR intervention effects on training-related views and resources (i.e., negative views of flexible work arrangements, perceptions of supervisors’ received family-supportive supervisor behaviors, and schedule control). Additionally, results did not support research questions 1, 2, and 3 in either direction, showing a lack of intervention effects on supervisors’ well-being (i.e., burnout and job satisfaction) and supervisors’ work-family interface (i.e., work-to-family conflict, family-to-work conflict, and work-to-family positive spillover).

Hypotheses 1, 2, and 3 focused on training-related views and resources that participation in STAR was expected to directly influence. Despite the lack of support for hypotheses of the current study, previous studies have shown STAR has significant impacts on employee-level schedule control, support for work-family needs, sleep time, and time with children (Kelly et al., 2014; Olson et al., 2015; Davis et al., 2015). Thus, it is not the case that STAR does not improve support for work-family needs and schedule control, but rather that STAR may have different effects for supervisors than for employees. STAR was designed with the explicit goal of improving these employee-level outcomes, and, as such, supervisor-level outcomes (i.e., outcomes targeted in the current study) may not be directly impacted.

Due to the intent-to-treat framework, the current study does not address whether supervisors' own supervisors were trained. Some supervisors in the sample held high- 
level positions in the organization and thus may not have traditional supervisor figures or may not interact with their supervisors in the same manner as lower level employeesupervisor relationships. If this is the case, it is unlikely that supervisors would experience increases in perceptions of received FSSBs and schedule control. Additionally, supervisors often have more control over their work and schedules than lower level employees, so there may not be as much potential for increasing schedule control and support for work-family needs as there would be in a lower level sample, due to high baseline levels. Mean levels of FSSBs and schedule control on scales of 1 to 5 at baseline were 3.87 and 3.33, respectively, indicating this may be the case, particularly regarding FSSBs.

Finally, because of the responsibilities supervisors had throughout participation in STAR, the lack of support for hypotheses 1, 2, and 3 may be due in part to an increase in job demands. Supervisors participated in many components of the STAR intervention-a commitment that may have increased the tasks and responsibilities of supervisors to a greater extent than employees. An increase in job demands would potentially counteract positive effects of the intervention for some supervisors, such as schedule control. Additionally, supervisors may see their responsibilities related to the intervention as counterproductive toward meeting their own work-family needs and thus may not perceive an increase in support. Future research should directly measure changes in supervisors' job demands due to participation in the intervention, as well as impacts of any existing change. 
Research questions 1, 2, and 3 were based in COR theory (Hobfoll, 1989), focusing on STAR intervention effects on supervisors’ well-being and work-family interface. COR theory proposes that strain results from threat to or loss of resources and that resources can buffer the effects of stressful situations. As suggested in the introduction of the current study, STAR may have simultaneously provided resources and caused threat to or loss of resources for supervisors. For example, STAR likely provided supervisors with new knowledge, skills, and abilities, but STAR likely simultaneously resulted in added responsibility for supervisors, which could have threatened or diminished resources such as valued family time. It is important for future research to explore potential mechanisms related to intervention effects on supervisors’ well-being and work-family interface, such as moderators that could explain differential experiences of resource losses and gains amongst supervisors.

Despite the lack of statistically significant effects on supervisor outcomes in the current study, it is important to note that even though there were no significant beneficial outcomes of the intervention for supervisors, there were also no significant iatrogenic effects on supervisors. The STAR intervention did not significantly reduce supervisors’ received FSSBs or schedule control, decrease well-being, increase work-family conflict, or decrease work-family positive spillover. Additionally, the vast majority of the results was in the ideal or expected direction. Because the STAR intervention was designed to improve employee-level outcomes, without explicit intention to directly improve supervisor-level outcomes, the lack of harmful effects on supervisors is reassuring for 
interventions targeted at improving employee outcomes through supervisor-level interventions. This lends support to future use of similar interventions and provides a solid foundation upon which to build future interventions that do specifically include intentions to improve supervisor outcomes.

\section{Limitations and Future Directions}

One potential limitation of the proposed study is the relatively small sample size. The number of supervisors in each condition may limit statistical conclusion validity. Because some of the effect sizes for outcome variables may be small, power is limited by the sample size. Due to use of archival data, addition of participants is not possible. Future studies should address this issue with larger sample sizes.

A second possible limitation of the current study is external validity. While there are advantages to using a sample of supervisors from an hourly, lower-wage industry, it is difficult to determine whether the results of the current study would be similar across other contexts. Other published research on the STAR intervention is based on implementation in the information technology industry (Kelly et al., 2014; Olson et al., 2015; Davis et al., 2015), where effects of STAR may be quite different. For example, schedule control may be more difficult to achieve in the extended care industry than in the information technology industry. Many job tasks of the sample assessed in the current study depend directly on patients' health needs, while job tasks in information technology and other more “white-collar” industries may be more flexible.

Furthermore, implementation of the STAR intervention is a complex and dynamic 
process. STAR was tailored slightly to each work site through participatory sessions and outside activities. Other interventions may face completely different challenges, leaving future applications of the results of the current study potentially limited. Future research should expand these investigations to include other interventions, including interventions focused on topics other than work-family needs.

Future research can also expand upon the current study by exploring supervisor experiences related to interventions in greater depth. First, because theoretical background suggests that supervisors can experience both resource gains and resource losses through interventions that include supervisor-specific training, exploration of moderators in the relations between intervention participation and supervisor outcomes should hold high priority. For example, supervisors' attitudes toward the intervention (e.g., "buy-in”) may moderate the link, such that those supervisors who view the intervention most positively are more likely to have favorable outcomes.

Other opportunities for future research include new outcome variables and multisource data. First, scholars might expand upon those outcomes assessed in the current study to examine other variables that may have significant impact on supervisors, such as objective health outcomes. Workplace interventions have been shown to influence health outcomes in other contexts, so exploration of health and other outcomes in supervisor samples specifically would reveal important information about the value of and potential challenges associated with interventions. Second, future research surrounding supervisor experiences of interventions should assess supervisor outcomes from multiple sources. 
Multi-source data is highly valued for its ability to reduce common method bias (e.g., Podsakoff, MacKenzie, Lee, \& Podsakoff, 2003), but can be very difficult to acquire. Aggregating employee reports of each supervisor's behaviors, such as FSSBs, and using measures of climate, such as work-family climate or training transfer climate, that account for the work group as a whole are potentially fruitful avenues for future research.

Another area of future research lies in exploration of crossover related to supervisors’ participation in interventions. While employee outcomes are more often explored, research has not yet examined how supervisor outcomes from interventions may cross over to employees. Furthermore, impacts of workplace interventions may expand from the supervisor to include the supervisor's spouse or family members. Future research should account for these potential impacts on the larger workplace and family systems.

Finally, future research should target the effects of intervention participation levels (e.g., “dosage”) on supervisor outcomes. The field of prevention science has proposed standards for evaluating intervention effectiveness (e.g., Flay et al., 2005), but use of evaluation techniques varies wildly across fields and across individual projects. Work-family interventions are rare, and high-quality implementation of these interventions is rarer still (Hammer, Kossek, Anger, Bodner, \& Zimmerman, 2011; Casper, Eby, Bordeaux, Lockwood, \& Lambert, 2007). Flay and colleagues (2005) argue that researchers have the ability to reduce "the most common and costly problems of human behavior” (p. 152) by determining how well interventions work, whether 
interventions are ready for widespread dissemination, and what further evidence would support widespread dissemination; through these processes, large-scale beneficial change can occur. Study of dosage can provide key information about what conditions are required to obtain observed outcomes of interventions (Flay et al., 2005). By examining the effect of intervention participation levels and dosage, future research will be able to provide practical recommendations for implementation of interventions, including insight into how best to maximize beneficial outcomes of work-family interventions for supervisors.

\section{Implications}

Results of the current study have several implications for both research and practice. First, further study of intervention outcomes for supervisors may help improve recruitment and buy-in efforts for future interventions at both the supervisor level and the organizational level. Previous meta-analytic research established training motivation as moderately to strongly related to training outcomes, such as declarative knowledge, skill acquisition, and transfer of training (Colquitt, LePine, \& Noe, 2000; Alliger, Tannenbaum, Bennett, Traver, \& Shetland, 1997). By understanding how supervisors are impacted by interventions, future implementation can be tailored to motivate supervisors to the greatest extent possible. If, for example, supervisors know participation in an intervention will benefit outcomes such as well-being for both employees and their selves, supervisors may be more motivated to participate in and buy into the training. Furthermore, organizations may be more likely to adopt new interventions if the 
interventions are known to improve outcomes across levels of organizations. Although the current study did not provide support for STAR intervention effects on supervisorlevel outcomes, future research can build upon the current study to help improve future interventions.

Finally, the current study has implications for the health and well-being of supervisors, as well as employees, organizations, and families. By improving supervisor outcomes through interventions and development opportunities, scholars and practitioners can effect change that meaningfully betters the lives of workers. The current study shows a lack of support for STAR intervention effects on supervisor outcomes, indicating that it is essential for future intervention designs to consider supervisors’ outcomes. Supervisors carry vast and varied responsibilities within organizations, leading to risk of experiencing increased work stress levels, with mid-level managers facing greater stress and anxiety than either top-level managers or frontline workers (Srivastava, Hagtvet, \& Sen, 1994). By addressing the impacts of interventions on supervisors directly, scholars and practitioners can design interventions that benefit more levels of the workplace than those interventions focusing on employees alone. These benefits have the potential to cross over to employees' and supervisors’ families, as well, effecting largescale change.

\section{Conclusion}

While norms surrounding work and family demands continue to develop and change, researchers and organizations are striving to improve the lives of workers 
through development of workplace policies, practices, and interventions. The current study examines supervisors, as an essential component of organizational structure, and their experiences of work-family interventions. By further exploring the experiences of supervisors in work-family interventions, researchers will be able to provide recommendations to improve future interventions and better improve the lives of workers across all levels of organizations, as well as their families. 
Figure 1

Hypothesized Model

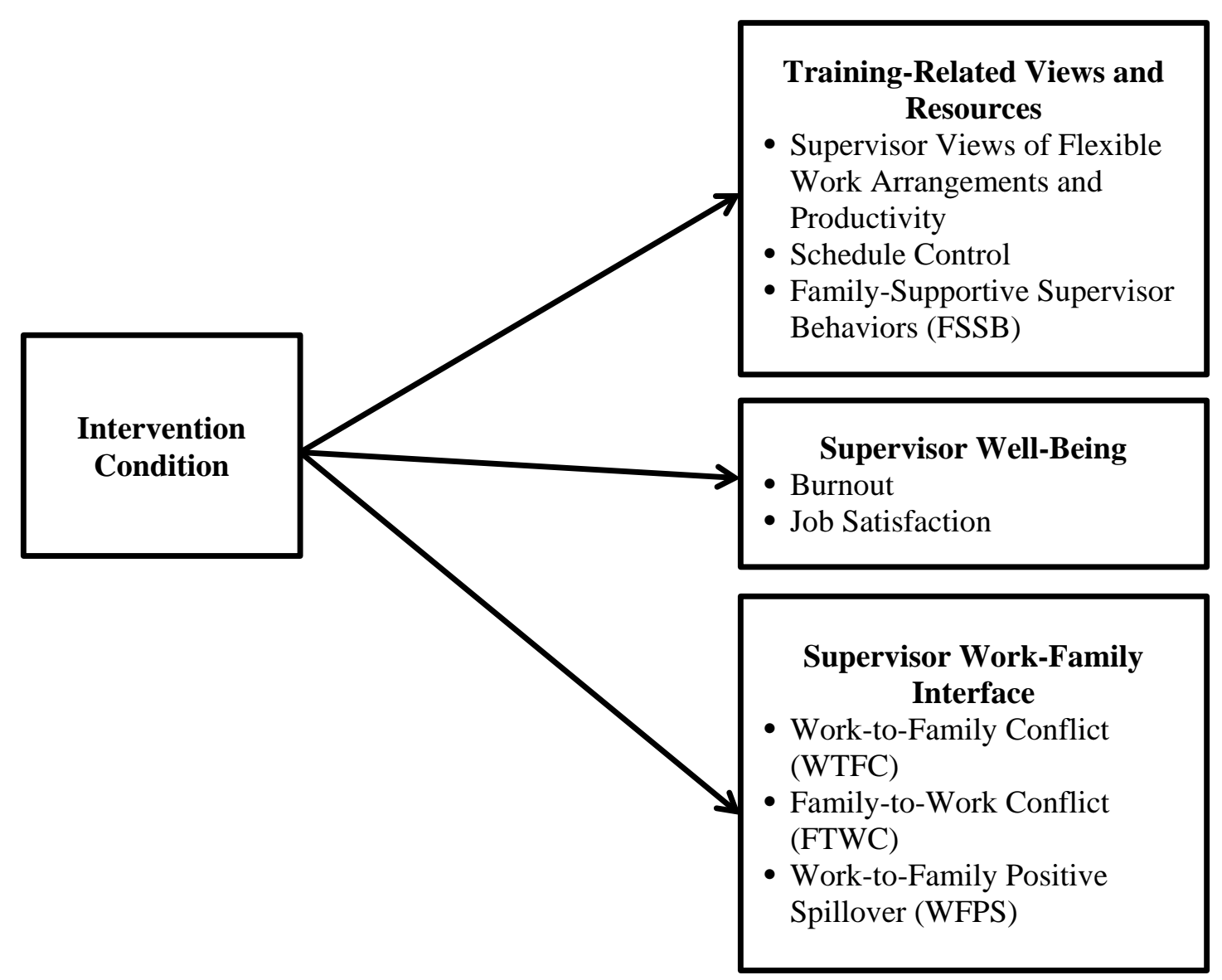


Table 1

Means by Condition Over Time

\begin{tabular}{llccc}
\hline Outcome & Condition & Baseline & 6 months & 12 months \\
\hline \multirow{2}{*}{ Views of FWAs } & Usual Practice & 2.92 & 2.85 & 2.83 \\
& Intervention & 2.91 & 2.83 & 2.82 \\
\cline { 2 - 4 } FSSBs & Usual Practice & 3.84 & 3.78 & 3.68 \\
& Intervention & 3.90 & 3.85 & 3.75 \\
\cline { 2 - 4 } Schedule Control & Usual Practice & 3.32 & 3.34 & 3.32 \\
& Intervention & 3.34 & 3.36 & 3.34 \\
\cline { 2 - 4 } Burnout & Usual Practice & 4.20 & 4.30 & 4.46 \\
& Intervention & 4.51 & 4.61 & 4.77 \\
\cline { 2 - 4 } Job Satisfaction & Usual Practice & 4.47 & 4.39 & 4.30 \\
\multirow{2}{*}{ WTFC } & Intervention & 4.27 & 4.19 & 4.10 \\
\cline { 2 - 4 } FTWC & Usual Practice & 2.83 & 2.87 & 2.81 \\
& Intervention & 3.26 & 3.29 & 3.23 \\
\cline { 2 - 4 } WFPS & Usual Practice & 1.97 & 1.92 & 1.87 \\
\cline { 2 - 4 } & Intervention & 2.06 & 2.02 & 3.97 \\
\cline { 2 - 4 } & Usual Practice & 3.97 & 3.94 & 3.94 \\
\cline { 2 - 4 } Ad & Intervention & 3.98 & 3.96 &
\end{tabular}

Notes: Adjusted means derived from general linear mixed model analysis results. FWA $=$

flexible work arrangement. FSSB = family-supportive supervisor behavior. WTFC = work-tofamily conflict. FTWC = family-to-work conflict. WFPS = work-to-family positive spillover. 
Table 2

Descriptive Statistics for and Correlations Among Key Study Variables

\begin{tabular}{|c|c|c|c|c|c|c|c|c|c|c|c|c|}
\hline & $M(S D)$ & 1 & 2 & 3 & 4 & 5 & 6 & 7 & 8 & 9 & 10 & 11 \\
\hline 1. Views of FWAs (T1) & $2.85(.84)$ & - & & & . & . & & & & & & \\
\hline 2. FSSBs (T1) & $3.87(.74)$ & -.04 & - & & . & & & & & & & \\
\hline 3. Sched. Control (T1) & $3.33(.80)$ & $-.21 *$ & $.23^{*}$ & - & & & & & & & & \\
\hline 4. Job Satisfaction (T1) & $4.37(.61)$ & $-.24^{*}$ & $.30 *$ & $.21^{*}$ & - & & & & & & & \\
\hline 5. Burnout (T1) & 4.34 (1.69) & $.26 *$ & $-.43 *$ & $-.27 *$ & $-.42 *$ & - & & & & & & \\
\hline 6. WTFC (T1) & $3.03(1.01)$ & $.18^{*}$ & $-.26 *$ & $-.27 *$ & $-.37 *$ & $.62 *$ & - & & & & & \\
\hline 7. FTWC (T1) & $2.01(.58)$ & $.17 *$ & -.13 & -.07 & $-.28 *$ & $.29 *$ & $.39 *$ & - & & & & \\
\hline 8. WFPS (T1) & $3.97(.65)$ & .07 & .05 & .10 & $.15^{*}$ & .08 & .11 & .03 & - & & & \\
\hline 9. Views of FWAs (T2) & $2.75(.81)$ & $.55^{*}$ & .02 & $-.29 *$ & $-.23 *$ & $.17^{*}$ & $.21^{*}$ & .14 & .11 & - & & \\
\hline 10. FSSBs (T2) & $3.86(.87)$ & -.07 & $.56^{*}$ & $.23^{*}$ & $.19 *$ & $-.16 *$ & $-.26 *$ & $-.19 *$ & .01 & -.09 & - & \\
\hline 11. Sched. Control (T2) & $3.34(.74)$ & -.20 & .12 & $.70^{*}$ & $.30 *$ & $-.24 *$ & $-.24 *$ & -.11 & -.04 & $-.25 *$ & $.34 *$ & - \\
\hline 12. Job Satisfaction (T2) & $4.34(.57)$ & -.17 & $.27 *$ & $.29 *$ & $.65^{*}$ & $-.41 *$ & $-.32 *$ & $-.22 *$ & .01 & $-.19 *$ & $.37 *$ & $.42 *$ \\
\hline 13. Burnout (T2) & $4.35(1.53)$ & .12 & $-.26 *$ & $-.18 *$ & $-.31 *$ & $.68 *$ & $.50 *$ & $.22 *$ & .08 & .14 & $-.22 *$ & $-.22 *$ \\
\hline 14. WTFC (T2) & $2.96(.98)$ & .08 & $-.19 *$ & $-.24 *$ & $-.23 *$ & $.44^{*}$ & $.68 *$ & $.22 *$ & $.20 *$ & $.16^{*}$ & $-.35 *$ & $-.27 *$ \\
\hline 15. FTWC (T2) & $1.99(.62)$ & .01 & -.07 & -.00 & $-.28 *$ & $.16^{*}$ & $.28 *$ & $.57 *$ & -.03 & .05 & $-.16^{*}$ & -.07 \\
\hline 16. WFPS (T2) & $3.99(.64)$ & -.02 & -.03 & .09 & .04 & .12 & .12 & -.01 & $.54 *$ & .04 & -.05 & -.06 \\
\hline 17. Views of FWAs (T3) & $2.85(.84)$ & $.47 *$ & .06 & -.16 & $-.24 *$ & .07 & .06 & .08 & -.02 & $.60 *$ & -.06 & $-.19 *$ \\
\hline 18. FSSBs (T3) & $3.80(.80)$ & -.14 & $.47^{*}$ & $.21^{*}$ & $.30 *$ & $-.24 *$ & $-.27 *$ & $-.33^{*}$ & -.00 & -.15 & $.61^{*}$ & $.19 *$ \\
\hline 19. Sched. Control (T3) & $3.30(.80)$ & $-.22 *$ & $.18^{*}$ & $.62 *$ & $.33 *$ & $-.18 *$ & $-.22 *$ & -.15 & .10 & $-.28 *$ & $.24 *$ & $.68 *$ \\
\hline 20. Job Satisfaction (T3) & $4.31(.66)$ & $-.24 *$ & $.24^{*}$ & $.29 *$ & $.61^{*}$ & $-.29 *$ & $-.30 *$ & $-.32 *$ & .12 & $-.21 *$ & .32 & $.31^{*}$ \\
\hline 21. Burnout (T3) & $4.29(1.62)$ & $.21 *$ & $-.18 *$ & $-.25 *$ & $-.32 *$ & $.60^{*}$ & $.38 *$ & $.26^{*}$ & -.00 & .15 & -.16 & $-.22 *$ \\
\hline 22. WTFC (Т3) & $2.83(.97)$ & .11 & -.16 & $-.22 *$ & $-.20 *$ & $.32 *$ & $.59 *$ & $.32 *$ & .12 & .15 & $-.35^{*}$ & $-.28 *$ \\
\hline 23. FTWC (T3) & $1.93(.58)$ & .12 & -.10 & -.12 & -.13 & $.21 *$ & $.27 *$ & $.53 *$ & -.07 & .12 & $-.17 *$ & $-.18 *$ \\
\hline 24. WFPS (T3) & $4.01(.56)$ & -.04 & .07 & .05 & .03 & .10 & .10 & -.02 & $.57 *$ & .09 & -.06 & -.04 \\
\hline
\end{tabular}

Note: $* p<.05$. Ns range from 139 to 184 due to occasional missing data. FWA = flexible work arrangement. FSSB = family-supportive supervisor behavior. WTFC $=$ work-to-family conflict. FTWC $=$ family-to-work conflict. WFPS = work-to-family positive spillover. T1 = time 1 (i.e., baseline). T2 = time 2 (i.e., 6 months following baseline). T3 = time 3 (i.e., 12 months following baseline). 
Table 2, cont.

Descriptive Statistics for and Correlations Among Key Study Variables

\begin{tabular}{|c|c|c|c|c|c|c|c|c|c|c|c|c|}
\hline & 12 & 13 & 14 & 15 & 16 & 17 & 18 & 19 & 20 & 21 & 22 & 23 \\
\hline \multicolumn{13}{|l|}{ 1. Views of FWAs (T1) } \\
\hline \multicolumn{13}{|l|}{ 2. FSSBs (T1) } \\
\hline \multicolumn{13}{|l|}{ 3. Schedule Control (T1) } \\
\hline \multicolumn{13}{|l|}{ 4. Job Satisfaction (T1) } \\
\hline \multicolumn{13}{|l|}{ 5. Burnout (T1) } \\
\hline \multicolumn{13}{|l|}{ 6. WTFC (T1) } \\
\hline \multicolumn{13}{|l|}{ 7. FTWC (T1) } \\
\hline \multicolumn{13}{|l|}{ 8. WFPS (T1) } \\
\hline \multicolumn{13}{|l|}{ 9. Views of FWAs (T2) } \\
\hline \multicolumn{13}{|l|}{ 10. FSSBs (T2) } \\
\hline \multicolumn{13}{|l|}{ 11. Schedule Control (T2) } \\
\hline 12. Job Satisfaction (T2) & - & & & & & & & & & & & \\
\hline 13. Burnout (T2) & $-.42 *$ & - & & & & & & & & & & \\
\hline 14. WTFC (T2) & $-.36 *$ & $.57 *$ & - & & & & & & & & & \\
\hline 15. FTWC (T2) & $-.22 *$ & $.23 *$ & $.29 *$ & - & & & & & & & & \\
\hline 16. WFPS (T2) & .03 & .11 & .15 & -.08 & - & & & & & & & \\
\hline 17. Views of FWAs (T3) & $-.22 *$ & .10 & .11 & .11 & -.06 & - & & & & & & \\
\hline 18. FSSBs (T3) & $.34^{*}$ & $-.22 *$ & $-.31 *$ & $-.24 *$ & -.03 & -.11 & - & & & & & \\
\hline 19. Schedule Control (T3) & $.28 *$ & -.16 & $-.21 *$ & -.02 & .04 & $-.21^{*}$ & $.32 *$ & - & & & & \\
\hline 20. Job Satisfaction (T3) & $.58 *$ & $-.34 *$ & $-.36 *$ & $-.32 *$ & .11 & $-.30 *$ & $.49 *$ & $.38 *$ & - & & & \\
\hline 21. Burnout (T3) & $-.27 *$ & $.67 *$ & $.39 *$ & .14 & .06 & .11 & $-.33 *$ & $-.26 *$ & $-.48 *$ & - & & \\
\hline 22. WTFC (T3) & $-.27^{*}$ & $.44^{*}$ & $.66^{*}$ & $.30 *$ & .09 & .14 & $-.46 *$ & $-.30 *$ & $-.43 *$ & $.54 *$ & - & \\
\hline 23. FTWC (T3) & -.08 & $.19 *$ & $.28 *$ & $.61^{*}$ & -.02 & .11 & $-.34 *$ & -.16 & $-.31 *$ & $.23 *$ & $.44^{*}$ & - \\
\hline 24. WFPS (T3) & -.09 & .02 & .08 & -.04 & $.48 * *$ & -.07 & .04 & .12 & .11 & -.03 & -.01 & $-.20 *$ \\
\hline
\end{tabular}


Table 3

General Linear Mixed Model Results for Intervention Effects on Supervisor Outcomes

\begin{tabular}{|c|c|c|c|c|c|c|c|c|}
\hline \multirow[b]{2}{*}{ Fixed Effects } & \multicolumn{2}{|c|}{ DV: Views of FWAs } & \multicolumn{2}{|c|}{ DV: FSSBs } & \multicolumn{2}{|c|}{ DV: Sched. Control } & \multicolumn{2}{|c|}{ DV: Burnout } \\
\hline & Estimate & $S E$ & Estimate & $S E$ & Estimate & $S E$ & Estimate & $S E$ \\
\hline Intercept & $2.923 *$ & 0.094 & $3.836^{*}$ & 0.085 & $3.320 *$ & 0.085 & 4.198* & 0.197 \\
\hline Intervention (at Baseline) & -0.016 & 0.136 & 0.065 & 0.122 & 0.018 & 0.123 & 0.313 & 0.283 \\
\hline 12 Month Wave (in Control Facilities) & -0.016 & 0.090 & -0.100 & 0.086 & -0.016 & 0.072 & 0.161 & 0.152 \\
\hline $\begin{array}{l}\text { Intervention * } 6 \text { Month Wave } \\
\quad \text { (6 Month Intervention Effect) }\end{array}$ & -0.134 & 0.128 & 0.048 & 0.123 & 0.102 & 0.102 & -0.056 & 0.216 \\
\hline Random Effects & Estimate & $S E$ & Estimate & $S E$ & Estimate & $S E$ & Estimate & $S E$ \\
\hline CS Diagonal Offset & $0.323^{*}$ & 0.027 & $0.298^{*}$ & 0.025 & $0.206^{*}$ & 0.017 & 0.927 & 0.076 \\
\hline CS Covariance & $0.376^{*}$ & 0.060 & $0.345^{*}$ & 0.054 & $0.407^{*}$ & 0.057 & 1.535 & 0.220 \\
\hline \multirow[t]{2}{*}{ Intercept Variance } & 0.022 & 0.032 & 0.006 & 0.023 & 0.013 & 0.027 & 0.189 & 0.133 \\
\hline & \multicolumn{2}{|c|}{ DV: Job Satisfaction } & \multicolumn{2}{|c|}{$\begin{array}{l}\text { DV: Work-to- } \\
\text { Family Conflict }\end{array}$} & \multicolumn{2}{|c|}{$\begin{array}{l}\text { DV: Family-to- } \\
\text { Work Conflict }\end{array}$} & \multicolumn{2}{|c|}{$\begin{array}{l}\text { DV: Work-to-Family } \\
\text { Positive Spillover }\end{array}$} \\
\hline 6 Month Wave (in Control Facilities) & -0.075 & 0.059 & 0.033 & 0.090 & -0.049 & 0.061 & -0.021 & 0.066 \\
\hline 12 Month Wave (in Control Facilities) & -0.090 & 0.060 & -0.059 & 0.092 & -0.046 & 0.062 & -0.022 & 0.067 \\
\hline $\begin{array}{l}\text { Intervention * } 6 \text { Month Wave } \\
\quad \text { (6 Month Intervention Effect) }\end{array}$ & 0.025 & 0.085 & -0.142 & 0.130 & 0.036 & 0.088 & 0.029 & 0.095 \\
\hline $\begin{array}{l}\text { Intervention * } 12 \text { Month Wave } \\
\quad \text { (12 Month Intervention Effect) }\end{array}$ & -0.018 & 0.087 & -0.181 & 0.133 & -0.047 & 0.090 & 0.106 & 0.097 \\
\hline Random Effects & Estimate & $S E$ & Estimate & $S E$ & Estimate & $S E$ & Estimate & $S E$ \\
\hline CS Diagonal Offset & $0.145^{*}$ & 0.012 & $0.337 *$ & 0.028 & $0.155 *$ & 0.013 & $0.180 *$ & 0.015 \\
\hline CS Covariance & $0.243^{*}$ & 0.033 & $0.525 *$ & 0.078 & $0.194^{*}$ & 0.027 & $0.215^{*}$ & 0.032 \\
\hline Intercept Variance & $\mathrm{NE}$ & $\mathrm{NE}$ & 0.098 & 0.057 & $\mathrm{NE}$ & $\mathrm{NE}$ & $\mathrm{NE}$ & $\mathrm{NE}$ \\
\hline
\end{tabular}

Note: $* p<.05$. FWA $=$ flexible work arrangement. FSSB $=$ family-supportive supervisor behavior. $N=139$ for all models except FSSBs $(N=137)$ and Schedule Control $(N=137)$. CS = Compound Symmetric. Intervention coded: $1=$ Intervention, $0=$ Control; 6 Month Wave coded: 1 = 6 Month Wave, 0 = Other; 12 Month Wave coded: $1=12$ Month Wave, $0=$ Other. NE = Not estimable due to lack of variability in estimated intercepts across facilities conditional on the other effects in the model. 


\section{References}

Ahola, K., Toppinen-Tanner, S., Huuhtanen, P., Koskinen, A., \& Väänänen, A. (2009). Occupational burnout and chronic work disability: An eight-year cohort study on pensioning among Finnish forest industry workers. Journal of Affective Disorders, 115, 150-159. doi:10.1016/j.jad.2008.09.021

Allen, T. D., Lapierre, L. M., Spector, P. E., Poelmans, S. A., O'Driscoll, M., Sanchez, J. I., ... \& Woo, J. M. (2014). The link between national paid leave policy and workfamily conflict among married working parents. Applied Psychology, 63, 5-28. doi:10.1111/apps.12004

Alliger, G. M., Tannenbaum, S. L, Bennett, W. Jr., Traver, H., \& Shetland, A. (1997). A meta-analysis of the relations among training criteria. Personnel Psychology, 50, 341-358.

Amstad, F. T., Meier, L. L., Fasel, U., Elfering, A., \& Semmer, N. K. (2011). A metaanalysis of work-family conflict and various outcomes with a special emphasis on cross-domain versus matching-domain relations. Journal of Occupational Health Psychology, 16, 151-169. doi:10.1037/a0022170

Barling, J., Christie, A., \& Hoption, A. (2010). Leadership. In S. Zedeck (Ed.) Handbook of Industrial and Organizational Psychology (pp. 183-240). Washington, DC: American Psychological Association.

Barton, K. A., Blanchard, E. B., \& Veazy, C. (1999). Self-monitoring as an assessment strategy in behavioral medicine. Psychological Assessment, 11, 490-497. 
doi:10.1037/1040-3590.11.4.490

Beehr, T. A., Farmer, S. J., Glazer, S., Gudanowski, D. M., \& Nair, V. N. (2003). The enigma of social support and occupational stress: Source congruence and gender role effects. Journal of Occupational Health Psychology, 8, 220-231. doi:10.1037/1076-8998.8.3.220

Bray, J. W., Kelly, E. L., Hammer, L. B., Almeida, D. M., Dearing, J. W., King, R. B., \& Buxton, O. M. (2013). An integrative, multilevel, and transdisciplinary research approach to challenges of work, family, and health. Methods report. Research Triangle Park, NC: RTI Press.

Brough, P., \& O'Driscoll, M. P. (2010). Organizational interventions for balancing work and home demands: An overview. Work \& Stress, 24, 280-297. doi:10.1080/02678373.2010.506808

Bruck, C. S., Allen, T. D., \& Spector, P. E. (2002). The relation between work-family conflict and job satisfaction: A finer-grained analysis. Journal of vocational Behavior, 60, 336-353. doi:10.1006/jvbe.2001.1836

Burke, R. J., \& Greenglass, E. R. (2001). Hospital restructuring, work-family conflict and psychological burnout among nursing staff. Psychology \& health, 16(5), 583-594. doi:10.1080/08870440108405528

Byron, K. (2005). A meta-analytic review of work-family conflict and its antecedents. Journal of Vocational Behavior, 67, 169-198. doi:10.1016/j.jvb.2004.08.009

Cammann, C., Fichman, M., Jenkins, G.D., \& Klesh, J. (1983). Michigan organizational 
assessment questionnaire. In S. E. Seashore, E. E., Lawler, P. H. Mirvis, \& C.

Cammann (Eds.), Assessing organizational change: A guide to methods, measures, and practices (pp. 71-138). New York: Wiley-Interscience.

Casper, W. J., Eby, L. T., Bordeaux, C., Lockwood, A., \& Lambert, D. (2007). A review of research methods in IO/OB work-family research. Journal of Applied Psychology, 92, 28-43. doi:10.1037/0021-9010.92.1.28

Cohen, J. (1988). Statistical power analysis for the behavioral sciences (2nd ed.). Hillsdale, NJ: Erlbaum.

Cohen, J., Cohen, P., West, S. G., \& Aiken, L. S. (2003). Applied multiple regression/correlation analysis for the behavioral sciences (3rd ed.). Mahwah, NJ: Erlbaum.

Colquitt, J. A., LePine, J. A., \& Noe, R. A. (2000). Toward an integrative theory of training motivation: a meta-analytic path analysis of 20 years of research. Journal of applied psychology, 85, 678-707. doi:10.1037//0021-9010.85.5.678

Davis, K. D., Lawson, K. M., Almeida, D. M., Kelly, E. L., King, R. B., Hammer, L., ... \& McHale, S. M. (2015). Parents’ daily time with their children: A workplace intervention. Pediatrics, 135, 875-882. doi:10.1542/peds.2014-2057

Edwards, J. R., \& Rothbard, N. P. (2000). Mechanisms linking work and family: Clarifying the relationship between work and family constructs. Academy of Management Review, 25, 178-199. doi:10.5465/AMR.2000.2791609

Flay, B. R., Biglan, A., Boruch, R. F., Castro, F. G., Gottfredson, D., Kellam, S., ... \& Ji, 
P. (2005). Standards of evidence: Criteria for efficacy, effectiveness and dissemination. Prevention science, 6(3), 151-175. doi:10.1007/s11121-005-5553$\mathrm{y}$

Freedy, J. R., \& Hobfoll, S. E. (1994). Stress inoculation for reduction of burnout: A conservation of resources approach. Anxiety, Stress and Coping, 6, 311-325. doi:10.1080/10615809408248805

Frone, M. R. (2003). Work-family balance. In J. C. Quick \& L. E. Tetrick (Eds.), Handbook of occupational health psychology (pp. 143-162). Washington, DC: American Psychological Association.

Grandey, A., Cordeiro, B., \& Crouter, A. (2005). A longitudinal and multi-source test of the work-family conflict and job satisfaction relationship. Journal of Occupational and Organizational Psychology, 78, 305-323. doi:10.1348/096317905X26769

Grandey, A. A., \& Cropanzano, R. (1999). The conservation of resources model applied to work-family conflict and strain. Journal of Vocational Behavior, 54(2), 350370. doi:10.1006/jvbe.1998.1666

Greenhaus, J. H., \& Beutell, N. J. (1985). Sources of conflict between work and family roles. Academy of Management Review, 10, 76-88. doi:10.5465/AMR.1985.4277352

Greenhaus, J. H., \& Powell, G. N. (2006). When work and family are allies: A theory of work-family enrichment. Academy of Management Review, 31, 72-92. 
doi:10.5465/AMR.2006.19379625

Halbesleben, J. R. (2006). Sources of social support and burnout: A meta-analytic test of the conservation of resources model. Journal of Applied Psychology, 91, 11341145. doi:10.1037/0021-9010.91.5.1134

Halpern, D. F. (2005). Psychology at the intersection of work and family: recommendations for employers, working families, and policymakers. American Psychologist, 60, 397-409. doi:10.1037/0003-066X.60.5.397

Hammer, L. B., Demsky, C. A., Kossek, E. E., \& Bray, J. (2015). Work-family intervention research. In T. D. Allen and L. T. Eby (Eds.). Oxford handbook of work and family. Oxford University Press.

Hammer, L.B., Kossek, E. E., Anger, W. K., Bodner, T., \& Zimmerman, K. (2011). Clarifying work-family intervention process: The roles of work-family conflict and family supportive supervisor behaviors. Journal of Applied Psychology, 96(1), 134-150. doi:10.1037/a0020927

Hammer, L. B., Kossek, E. E., Bodner, T., \& Crain, T. (2013). Measurement development and validation of the Family Supportive Supervisor Behavior ShortForm (FSSB-SF). Journal of Occupational Health Psychology, 18, 285-297. doi:10.1037/a0032612

Hammer, L.B., Kossek, E. E., Yrgaui, N. L., Bodner, T. E., \& Hanson, G. C. (2009). Development and validation of a multidimensional measure of family supportive supervisor behaviors (FSSB). Journal of Management, 35(4), 837-856. 
Hammer, L. B., Kossek, E. E., Zimmerman, K., \& Daniels, R. (2007). Clarifying the construct of family-supportive supervisory behaviors (FSSB): A multilevel perspective. Research in Occupational Stress and Well-Being, 6, 165-204.

Hanson, G.C., Hammer, L. B., and Colton, C. L. (2006). Development and validation of a multidimensional scale of perceived work-family positive spillover. Journal of Occupational Health Psychology, 11(3), 249-265. doi:10.1037/10768998.11.3.249

Hobfoll, S.E. (1989). Conservation of resources: A new attempt at conceptualizing stress. American Psychologist, 44, 513-524.

Hobfoll, S. E. (1998). Stress, culture, and community: The psychology and philosophy of stress. New York, NY: Plenum.

Hobfoll, S. E., Freedy, J., Lane, C., \& Geller, P. (1990). Conservation of social resources: Social support resource theory. Journal of Social and Personal Relationships, 7(4), 465-478. doi:10.1177/0265407590074004

Hobfoll, S. E., \& Shirom, A. (2001). Conservation of resources theory: Applications to stress and management in the workplace. In A. Shirom \& R. T. Golembiewski (Eds.), Handbook of organizational behavior (pp. 57-80). New York, NY: Marcel Dekker.

Innstrand, T. S., Langballe, E. M., Espnes, A. G., Falkum, E., \& Aasland, G. O. (2008). Positive and negative work-family interaction and burnout: A longitudinal study of reciprocal relations. Work \& Stress, 22, 1-15. 
doi:10.1080/02678370801975842

Kelly, E. L. \& Kalev, A. (2006). Managing flexible work arrangements in US organizations: Formalized discretion or "a right to ask”. Socio-Economic Review, 4, 379-416.

Kelly, E. L., Kossek, E. E., Hammer, L. B., Durham, M., Bray, J., Chermack, K., ... \& Kaskubar, D. (2008). Getting there from here: Research on the effects of workfamily initiatives on work-family conflict and business outcomes. The Academy of Management Annals, 2, 305-349. doi:10.1080/19416520802211610

Kelly, E. L., \& Moen, P. (2007). Rethinking the clockwork of work: Why schedule control may pay off at work and at home. Advances in Developing Human Resources, 9, 487-506. doi:10.1177/1523422307305489

Kelly, E. L., Moen, P., Oakes, J. M., Fan, W., Okechukwu, C., Davis, K. D., ... \& Casper, L. M. (2014). Changing work and work-family conflict: Evidence from the Work, Family, and Health Network. American Sociological Review, 1-32. doi:10.1177/0003122414531435

Kelly, E. L., Moen, P., \& Tranby, E. (2011). Changing workplaces to reduce work-family conflict schedule control in a white-collar organization. American Sociological Review, 76, 265-290. doi:10.1177/0003122411400056

King, R. B., Karuntzos, G., Casper, L. M., Moen, P., Davis, K. D., Berkman, L., ... \& Kossek, E. E. (2012). Work-family balance issues and work-leave policies. In R. J. Gatchel \& I. Z. Schultz, Handbook of occupational health and wellness (pp. 
323-339). Springer US.

Klein, K. J., \& Kozlowski, S. W. (2000). From micro to meso: Critical steps in conceptualizing and conducting multilevel research. Organizational research methods, 3, 211-236. doi:10.1177/109442810033001

Klein, H. J., Noe, R. A., \& Wang, C. (2006). Motivation to learn and course outcomes: The impact of delivery mode, learning goal orientation, and perceived barriers and enablers. Personnel Psychology, 59, 665-702. doi:10.1111/j.17446570.2006.00050.x

Korotitsch, W. J., \& Nelson-Gray, R. O. (1999). An overview of self-monitoring research in assessment and treatment. Psychological Assessment, 11, 415-425. doi:10.1037/1040-3590.11.4.415

Kossek, E. E., Barber, A. E., \& Winters, D. (1999). Using flexible schedules in the managerial world: The power of peers. Human Resource Management, 38(1), 3346.

Kossek, E. E., Hammer, L. B., Kelly, E. L., \& Moen, P. (2014). Designing work, family \& health organizational change initiatives. Organizational Dynamics, 43, 53-63.

Kossek, E. E., \& Lambert, S. J. (2005). Work-family scholarship: Voice and context. In E. E. Kossek and S. J. Lambert (Eds.), Work and life integration: Organizational, cultural, and individual perspectives (pp. 3-18). Mahwah, NJ: Lawrence Erlbaum Associates.

Kossek, E. E., Pichler, S., Bodner, T., \& Hammer, L. B. (2011). Workplace social 
support and work-family conflict: A meta-analysis clarifying the influence of general and work-family-specific supervisor and organizational support. Personnel Psychology, 64, 289-313. doi:10.1111/j.1744-6570.2011.01211.x

Lambert, S., \& Waxman, E. (2005). Organizational stratification: Distributing opportunities for work-life balance. In Work and Life Integration: Organizational, Cultural, and Individual Perspectives (pp. 103-126). Mahwah, NJ: Erlbaum.

LaMontagne, A. D., Keegel, T., Louie, A. M., Ostry, A., \& Landsbergis, P. A. (2007). A systematic review of the job-stress intervention evaluation literature, 1990-2005. International Journal of Occupational and Environmental Health, 13, 268-280.

Laschinger, H. K., Almost, J., Purdy, N., \& Kim, J. (2004). Predictors of nurse managers' health in Canadian restructured healthcare settings. Nursing leadership, 17(4), 88105.

Maslach, C. (1982). Burnout: The cost of caring. New York, NY: Prentice-Hall.

Maslach C. 1998. A multidimensional theory of burnout. In C. L. Cooper, Theories of organizational stress (pp. 68-85). Oxford, UK: Oxford University Press.

Maslach, C., and Jackson, S. (1986). Maslach Burnout Inventory Manual, Second Edition. Palo Alto, CA: Consulting Psychologists Press.

Maslach, C., Schaufeli, W. B., \& Leiter, M. P. (2001). Job burnout. Annual Review of Psychology, 52, 397-422. doi:10.1146/annurev.psych.52.1.397

Mesmer-Magnus, J. R., \& Viswesvaran, C. (2005). Convergence between measures of work-to-family and family-to-work conflict: A meta-analytic examination. 
Journal of Vocational Behavior, 67, 215-232. doi:10.1016/j.jvb.2004.05.004

Moen, P., Kelly, E. L., Tranby, E., \& Huang, Q. (2011). Changing work, changing health: Can real work-time flexibility promote health behaviors and well-being?. Journal of Health and Social Behavior, 52, 404-429. doi:10.1177/0022146511418979

Neal, M. B., \& Hammer, L. B. (2007). Working couples caring for children and aging parents: Effects on work and well-being. Mahwah, NJ: Lawrence Erlbaum Associates.

Netemeyer, R. G., Boles, J. S., and McMurrian, R. (1996). Development and validation of work-family conflict and family-work conflict scales. Journal of Applied Psychology, 81(4), 400-410.

Olson, R., Crain, T. L., Bodner, T. E., King, R., Hammer, L. B., Klein, L. C., ... \& Buxton, O. M. (2015). A workplace intervention improves sleep: Results from the randomized controlled Work, Family, and Health Study. Sleep Health, 1, 55-65. doi:10.1016/j.sleh.2014.11.003

Olson, R., \& Winchester, J. (2008). Behavioral self-monitoring of safety and productivity in the workplace: A methodological primer and quantitative literature review. Journal of Organizational Behavior Management, 28(1), 9-75. doi:10.1080/01608060802006823

Podsakoff, P. M., MacKenzie, S. B., Lee, J. Y., \& Podsakoff, N. P. (2003). Common method biases in behavioral research: a critical review of the literature and recommended remedies. Journal of Applied Psychology, 88, 879-904. 
doi:10.1037/0021-9010.88.5.879

Poghosyan, L., Aiken, L. H., \& Sloane, D. M. (2009). Factor structure of the Maslach Burnout Inventory: An analysis of data from large scale cross-sectional surveys of nurses from eight countries. International Journal of Nursing Studies, 46, 894902. doi:10.1016/j.ijnurstu.2009.03.004

Price, J. L. (2001). Reflections on the determinants of voluntary turnover. International Journal of Manpower, 22, 600-624. doi:10.1108/EUM0000000006233

Scharf, T., Chapman, L., Collins, J., Limanowski, J., Heaney, C., \& Goldenhar, L. M. (2008). Intervention effectiveness evaluation criteria: Promoting competitions and raising the bar. Journal of Occupational Health Psychology, 13, 1-9. doi:10.1037/1076-8998.13.1.1

Srivastava, S., Hagtvet, K. A., \& Sen, A. K. (1994). A study of role stress and job anxiety among three groups of employees in a private sector organization. Social Science International, 10, 25-30.

Shirom, A. (2009). Burnout and health: expanding our knowledge. Stress and Health, 25, 281-285. doi:10.1002/smi.1283

Shockley, K. M., \& Allen, T. D. (2007). When flexibility helps: Another look at the availability of flexible work arrangements and work-family conflict. Journal of Vocational Behavior, 71(3), 479-493. doi:10.1016/j.jvb.2007.08.006

Spector, P. (1997). Job satisfaction: Application, assessment, cause and consequences. London, UK: Sage. 
Tabachnick, B. G., \& Fidell, L. S. (2007). Using multivariate statistics (5th ed.). Boston, MA: Pearson Education.

Thomas, L. T., \& Ganster, D. C. (1995). Impact of family-supportive work variables on work-family conflict and strain: a control perspective. Journal of Applied Psychology, 80, 6-15.

Wayne, J. H., Grzywacz, J. G., Carlson, D. S., \& Kacmar, K. M. (2007). Work-family facilitation: A theoretical explanation and model of primary antecedents and consequences. Human Resource Management Review, 17, 63-76. doi:10.1016/j.hrmr.2007.01.002

Westman, M., Hobfoll, S. E., Chen, S., Davidson, O. B., \& Laski, S. (2004). Organizational stress through the lens of conservation of resources (COR) theory. Research in occupational stress and well-being, 4, 167-220. doi:10.1016/S14793555(04)04005-3 
Appendix

Survey Items

\section{Supervisor Views of the Effect of Flexible Work Arrangements on Productivity} (Kossek, Barber, \& Winters, 1999)

Stem: "You worry that allowing more flexibility around hours of work would..."

\begin{tabular}{|c|l|}
\hline $\begin{array}{c}\text { Variable } \\
\text { Name }\end{array}$ & \multicolumn{1}{c|}{ Item text } \\
\hline MW_VIEW1 & $\ldots$ increase your workload \\
\hline MW_VIEW2 & $\ldots$ create problems among your subordinates \\
\hline MW_VIEW3 & $\ldots$ cause staffing headaches \\
\hline MW_VIEW4 & $\ldots$ increase your costs \\
\hline MW_VIEW5 & $\begin{array}{l}\text {...make it more difficult for your employees to reach their } \\
\text { objectives }\end{array}$ \\
\hline MW_VIEW6 & $\begin{array}{l}\text { If you allow my subordinates to use flexible work schedules, you } \\
\text { would be understaffed }\end{array}$ \\
\hline
\end{tabular}

5=Strongly Agree

4=Agree

$3=$ Neither agree nor disagree

$2=$ Disagree

1=Strongly Disagree

Higher scores reflect stronger views that flexibility would negatively impact productivity.

Job Satisfaction (Cammann, Fichman, Jenkins, \& Klesh, 1983)

Instructions: The next set of questions will ask about how satisfied you are with your job at your company.

\begin{tabular}{|c|l|}
\hline $\begin{array}{c}\text { Variable } \\
\text { Name }\end{array}$ & \multicolumn{1}{c|}{ Item text } \\
\hline MW_JSAT1 & In general, you like working at your job. \\
\hline MW_JSAT2 & In general, you are satisfied with your job \\
\hline MW_JSAT3 & $\begin{array}{l}\text { You are generally satisfied with the kind of work you do in this } \\
\text { job. }\end{array}$ \\
\hline
\end{tabular}

Strongly Agree $\quad=5$

Agree $\quad=4$

Neither $=3$ 
Disagree $\quad=2$

Strongly Disagree $\quad=1$

Higher scores reflect greater job satisfaction.

Maslach Burnout Inventory, Emotional Exhaustion (Maslach \& Jackson, 1986) Instructions: Next we will talk about how your work makes you feel.

\begin{tabular}{|c|l|}
\hline $\begin{array}{c}\text { Variable } \\
\text { Name }\end{array}$ & \multicolumn{1}{c|}{ Item text } \\
\hline MW_BURN1 & $\begin{array}{l}\text { You feel emotionally drained from your work. How often do you } \\
\text { feel this way? }\end{array}$ \\
\hline MW_BURN2 & $\begin{array}{l}\text { You feel burned out by your work. How often do you feel this } \\
\text { way? }\end{array}$ \\
\hline MW_BURN3 & $\begin{array}{l}\text { You feel used up at the end of the workday. How often do you } \\
\text { feel this way? }\end{array}$ \\
\hline
\end{tabular}

Recoded Items:

Every day $\quad=7$

A few times a week $\quad=6$

Once a week $=5$

A few times a month $\quad=4$

Once a month or less $\quad=3$

A few times a year or less $=2$

Never $\quad=1$

Higher scores reflect greater burnout.

FSSB-SF (Hammer, Kossek, Bodner, \& Crain, 2013)

Instructions: I'm now going to read some statements about your experiences with your direct supervisor at your company.

INTERVIEWER, IF ASKED: (By non-work, we mean your family and your personal or free time.)

\begin{tabular}{|c|l|}
\hline $\begin{array}{c}\text { Variable } \\
\text { Name }\end{array}$ & \multicolumn{1}{c|}{ Item text } \\
\hline MW_FSSB1 & $\begin{array}{l}\text { Your supervisor makes you feel comfortable talking to him/her } \\
\text { about my conflicts between work and non-work. }\end{array}$ \\
\hline MW_FSSB3 & $\begin{array}{l}\text { Your supervisor works effectively with employees to creatively } \\
\text { solve conflicts between work and non-work. }\end{array}$ \\
\hline MW_FSSB4 & Your supervisor demonstrates effective behaviors in how to \\
\hline
\end{tabular}




\begin{tabular}{|l|l|}
\hline & juggle work and non-work issues. \\
\hline MW_FSSB5 & $\begin{array}{l}\text { Your supervisor organizes the work in your department or unit to } \\
\text { jointly benefit employees and the company. }\end{array}$ \\
\hline
\end{tabular}

Strongly agree $\quad=5$

Agree $\quad=4$

Neither $\quad=3$

Disagree $\quad=2$

Strongly Disagree $\quad=1$

Higher scores reflect greater FSSB.

\section{Schedule Control (adapted from Thomas \& Ganster, 1985}

Instructions: The first few questions are going to ask about your perceived control over your work schedule at your company.

PROMPT FOR QUESTIONS: (Please answer thinking about what you feel or believe is realistic for you, in your job.)

\begin{tabular}{|c|l|}
\hline $\begin{array}{c}\text { Variable } \\
\text { Name }\end{array}$ & \multicolumn{1}{c|}{ Item text } \\
\hline MW_CWH1 & $\begin{array}{l}\text { How much choice do you have over when you take vacations or } \\
\text { days off? }\end{array}$ \\
\hline MW_CWH2 & $\begin{array}{l}\text { How much choice do you have over when you can take off a few } \\
\text { hours? }\end{array}$ \\
\hline MW_CWH3 & $\begin{array}{l}\text { How much choice do you have over when you begin and end } \\
\text { each work day? }\end{array}$ \\
\hline MW_CWH4 & $\begin{array}{l}\text { How much choice do you have over the total number of hours } \\
\text { you work each week? }\end{array}$ \\
\hline MW_CWH5 & $\begin{array}{l}\text { How much choice do you have over doing some of your work at } \\
\text { home or at another location, instead of [insert company } \\
\text { name/location]? }\end{array}$ \\
\hline MW_CWH6 & $\begin{array}{l}\text { How much choice do you have over the number of personal } \\
\text { phone calls you make or receive while you work? }\end{array}$ \\
\hline MW_CWH7 & $\begin{array}{l}\text { How much choice do you have over the amount or times you take } \\
\text { work home with you? }\end{array}$ \\
\hline MW_CWH8 & $\begin{array}{l}\text { How much choice do you have over shifting to a part-time } \\
\text { schedule (or full-time if currently part-time) while remaining in } \\
\text { your current position if you wanted to do so? }\end{array}$ \\
\hline
\end{tabular}

Very Much $\quad=5$

Much $\quad=4$

A moderate amount $\quad=3$ 
Little $\quad=2$

Very little $\quad=1$

Higher scores reflect greater control over work hours.

WFC (Netemeyer, Boles, \& McMurrian, 1996)

Instructions: The next section will ask you some questions about how your job relates to your family or personal life.

Please continue using response card \#10 and think about the past 6 months.

\begin{tabular}{|c|l|}
\hline $\begin{array}{c}\text { Variable } \\
\text { Name }\end{array}$ & \multicolumn{1}{c|}{ Item text } \\
\hline MW_WFC1 & $\begin{array}{l}\text { The demands of your work interfere with your family or personal } \\
\text { time. }\end{array}$ \\
\hline MW_WFC2 & $\begin{array}{l}\text { The amount of time your job takes up makes it difficult to fulfill } \\
\text { your family or personal responsibilities. }\end{array}$ \\
\hline MW_WFC3 & $\begin{array}{l}\text { Things you want to do at home do not get done because of the } \\
\text { demands your job puts on you }\end{array}$ \\
\hline MW_WFC4 & $\begin{array}{l}\text { Your job produces strain that makes it difficult to fulfill your } \\
\text { family or personal duties. }\end{array}$ \\
\hline MW_WFC5 & $\begin{array}{l}\text { Due to your work-related duties, you have to make changes to } \\
\text { your plans for family or personal activities. }\end{array}$ \\
\hline MW_WFC6 & $\begin{array}{l}\text { The demands of your family or personal relationships interfere } \\
\text { with work-related activities. }\end{array}$ \\
\hline MW_WFC7 & $\begin{array}{l}\text { You have to put off doing things at work because of demands on } \\
\text { your time at home. }\end{array}$ \\
\hline MW_WFC8 & $\begin{array}{l}\text { Things you want to do at work don't get done because of the } \\
\text { demands of your family or personal life. }\end{array}$ \\
\hline MW_WFC9 & $\begin{array}{l}\text { Your home life interferes with your responsibilities at work, such } \\
\text { as getting to work on time, accomplishing daily tasks, and } \\
\text { working overtime. }\end{array}$ \\
\hline MW_WFC10 & $\begin{array}{l}\text { Family-related strain interferes with your ability to perform job- } \\
\text { related duties. }\end{array}$ \\
\hline
\end{tabular}

$\begin{array}{ll}\text { Strongly Agree } & =5 \\ \text { Agree } & =4 \\ \text { Neither } & =3 \\ \text { Disagree } & =2 \\ \text { Strongly Disagree } & =1\end{array}$

Higher scores reflect greater work-family conflict. 
WFPS (Hanson, Hammer, \& Colton, 2004)

Continuation of Work-Family Conflict questions; no additional instructions

\begin{tabular}{|c|l|}
\hline $\begin{array}{c}\text { Variable } \\
\text { Name }\end{array}$ & \multicolumn{1}{c|}{ Item text } \\
\hline MW_WFPS1 & $\begin{array}{l}\text { When things are going well at work, your outlook regarding your } \\
\text { family or personal life is improved. }\end{array}$ \\
\hline MW_WFPS2 & $\begin{array}{l}\text { Being in a positive mood at work helps you to be in a positive } \\
\text { mood at home. }\end{array}$ \\
\hline MW_WFPS3 & Being happy at work helps you to be happy at home. \\
\hline MW_WFPS4 & $\begin{array}{l}\text { Having a good day at work allows you to feel positive with your } \\
\text { family. }\end{array}$ \\
\hline
\end{tabular}

Strongly Agree $\quad=5$

Agree $\quad=4$

Neither $\quad=3$

Disagree $\quad=2$

Strongly Disagree $\quad=1$

Higher scores reflect greater work-family positive spillover. 